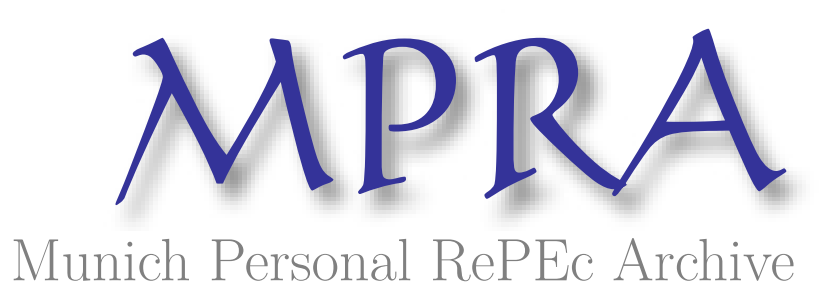

\title{
Sunk Cost Fallacy in Driving the World's Costliest Cars
}

Ho, Teck Hua and Png, Ivan P. L. and Reza, Sadat

2 March 2017

Online at https://mpra.ub.uni-muenchen.de/82139/

MPRA Paper No. 82139, posted 04 Dec 2017 07:23 UTC 


\title{
Sunk Cost Fallacy in Driving the World's Costliest Cars
}

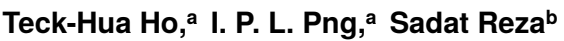 \\ a National University of Singapore, Singapore 119077; ' ${ }^{\mathbf{b}}$ Institute on Asian Consumer Insight, Nanyang Technological University, \\ Singapore 639798 \\ Contact: dprhoth@nus.edu.sg (T-HH); ipng@nus.edu.sg (IPLP); sreza@ntu.edu.sg (SR)
}

Received: June 17, 2016

Accepted: August 25, 2016

Published Online in Articles in Advance: March 2, 2017

https://doi.org/10.1287/mnsc.2016.2651

Copyright: (C) 2017 INFORMS

\begin{abstract}
We develop a behavioral model of durable good usage with mental accounting for sunk costs. It predicts higher-than-rational usage that attenuates at a rate that increases with sunk costs. Singapore government policy varied the sunk cost of buying a new car. Using Singapore data, we estimate the elasticity of driving with respect to sunk costs to be 0.048 , which implies that government policy between 2009 and 2013 was associated with 86 kilometers per month, or $5.6 \%$, more driving. The results are robust to specifying sunk costs as relative to buyer income and estimation with Hong Kong data. We believe this to be the first field evidence of the sunk cost fallacy in usage of a major durable good.
\end{abstract}

History: Accepted by John List, behavioral economics.

Funding: T.-H. Ho acknowledges funding from the Singapore National Research Foundation's Returning Singaporean Scientists Scheme [Grant NRF-RSS2014-001].

Supplemental Material: The online appendix is available at https://doi.org/10.1287/mnsc.2016.2651.

Keywords: sunk costs - mental accounting - behavioral economics • durable goods • consumer choice

\section{Introduction}

[C] ustomers who had initially paid more for a season subscription to a theater series attended more plays during the next 6 months, presumably because of their higher sunk cost in the season tickets. - -(Arkes and Blumer 1985, p. 124)

Economists and psychologists have long been interested in the effect of sunk costs on consumer choice and organizational behavior (Thaler 1980 and 1990). The sunk cost fallacy arises when individual actions are influenced by costs that have already been incurred and cannot be reversed. The actions serve to amortize the psychological burden of the (irreversible) cost in a mental account. Since sunk costs are irreversible, they should not play any role in rational decision making. Yet sunk costs have been implicated in apparently irrational decisions across multiple contexts.

In what Eyster (2002) described as the "most convincing single experiment" (p. 8), Arkes and Blumer (1985) gave unannounced price discounts at random to people buying season tickets at a university theater. Over the first half of the season, individuals who paid full price attended more shows than those who received discounts (4.1 vis-à-vis 3.3 of 5 shows). In the second half of the season, however, the two groups did not behave differently. Gourville and Soman (1998) observed "payment depreciation" among members of an athletic club: monthly attendance peaked when the members paid their half-yearly installment and then declined with time. In a field experiment at an allyou-can-eat-pizza restaurant, people who received a discount ate less (Just and Wansink 2011). The three studies suggest that sunk costs influence consumption. The first two studies also indicate that the effect of sunk costs declines over time.
However, in other field experiments, consumers given random unannounced discounts did not evince the sunk cost fallacy. Differences in the amounts that Zambian consumers paid for Clorin, a chemical to treat drinking water, did not affect their use of the chemical (Ashraf et al. 2010). In Kenya, there was no clear relation between the net price that consumers paid for insecticide-treated bed nets and their use of the nets (Cohen and Dupas 2010). ${ }^{1}$

What about the effect of sunk costs on the usage of a big-ticket durable good? Does amortization of the mental account for sunk costs lead the decision maker to increase or reduce usage over time?

The effect of sunk costs on decision making in repeated situations such as durable good usage has important implications for management of businesses and public administration as well as consumer behavior. ${ }^{2}$ However, the issue remains an open question, both in theory and empirically. Although Cohen and Dupas (2010) studied the use of bed nets, which are durable, they recorded usage just once. The Arkes and Blumer (1985) experiment and Gourville and Soman (1998) study pertain to usage of a facility, which differs from a durable good in that increased consumption does not affect the subsequent availability or quality of the good. Buyers of season tickets and members of the athletic club would not attend less to stretch out use of the facility.

Here, we investigate whether sunk costs influence use of a durable good in the context of the Singapore car market. Car usage is an attractive setting for investigation of the relation between sunk costs and durable good usage. People have many years of 
experience with cars, and usage is sustained over long periods of time. For instance, consumers engage in mental accounting when buying gasoline (Hastings and Shapiro 2013), and they are subject to projection bias and salience when buying new cars (Busse et al. 2015). The Singapore context is particularly attractive for several reasons. By design, government policies to restrict car ownership require buyers of new cars to make payments that are only partially refundable and so impose explicit sunk costs. Over time, these policies have generated substantial variation in the sunk costs incurred in new car purchases (and, incidentally, caused Singapore cars to become the world's most expensive; see Agarwal and Qian 2014). The government policies are long-standing and are repeatedly publicized, and thus, the sunk costs are certainly salient to people in Singapore.

To investigate the effect of sunk costs, we first develop a behavioral model of mental accounting to understand how sunk costs might influence usage of a durable good over time. The model stipulates that, over some time horizon (Gourville and Soman 1998, Thaler 1999), buyers mentally account for the sunk cost of the durable good. The model posits that the psychological burden of mental accounting depends on the sunk cost, cumulative usage, and their interaction. Under a specific condition, the model implies that car usage increases with the sunk cost and attenuates over time and, importantly, that the rate of attenuation over time increases with the sunk cost. This behavioral model of mental accounting nests rational behavior, where sunk costs do not affect decision making, as a special case.

Second, we take the behavioral model to structural estimation on a large-scale observational data set comprising an unbalanced panel of 8,264 cars belonging to a single brand that were sold in Singapore between 2000 and 2013. For each car, we have the accumulated driving (in kilometers) at each service with the car dealer. In the estimation, we exploit two sources of variation-differences in the sunk costs between cars within months and changes in sunk costs over time due to the continuing application of government policies. In a major extension, we specify sunk costs as relative to buyer's income, proxied by home prices, and exploit cross-sectional differences and time-series changes in home prices as another source of variation in (relative) sunk costs.

Figure 1 depicts average monthly usage with age for cars purchased between 2003 and 2005, as the sunk cost of buying cars decreased. ${ }^{3}$ Evidently, by Figure 1, driving was uniformly higher for cars with higher sunk costs, driving attenuated with age of the car, and the rate of attenuation was higher with higher sunk costs.

Our structural estimates suggest that the elasticity of usage with respect to the sunk cost of a car is 0.048 (s.e. 0.016). An increase in the sunk cost by $\mathrm{S} \$ 13,038$
Figure 1. Average Monthly Usage by Car Age

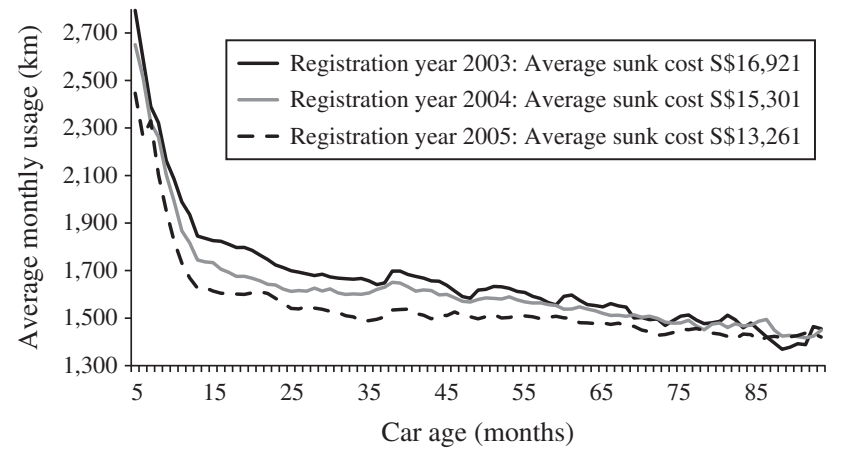

Note. For the most popular model in the sample (3,403 cars).

(the outcome of government policy between 2009 and 2013) would be associated with an increase in monthly driving by 86 kilometers, or $5.6 \%$, in the first four years of ownership.

We interpret the relation between the attenuation of usage and the sunk cost as being due to mental accounting for sunk costs. An obvious challenge to our interpretation is some form of selection. In particular, when government policies cause the prices of cars to increase, the people who buy cars are those who want to drive more, and so, higher sunk costs are associated with more driving. We address this selection explanation in several ways. First, the behavioral model implies that the rate at which usage attenuates with the age of the car increases with the sunk cost. By contrast, selection need not imply any relation between car prices and the rate of attenuation. Second, we estimate the structural model in terms of first differences, rather than the levels of driving, and so abstract from any buyer-specific fixed effect. Third, we explicitly test and reject three alternative explanations based on selection-people who pay more for cars being subject to relatively more intense hedonic adaptation (Frederick and Lowenstein 1999), demand shocks leading people to buy cars at high prices followed by reversion to the mean driving intensity, and high initial driving leading to more frequent breakdowns and attenuation of driving.

In the Singapore context, the sunk costs are so large that their influence on behavior might depend on the buyer's income. With this motivation, we extend the behavioral model to specify sunk costs as relative to household income, proxied by home prices. This extension exploits variation in both sunk costs and home prices to identify the effect of (relative) sunk costs. Importantly, the extension further mitigates concern about selection by car prices as housing prices are not related to car prices. We find that, consistent with the behavioral model, driving and the rate of attenuation with the age of the car increase with relative sunk costs.

Yet another possible interpretation of our empirical results distinguishes car buyers who differ in 
prior experience. The sunk cost fallacy is generally related to the endowment effect in the sense that the amount that the buyer has sunk can be viewed as an endowment (Genesove and Mayer 2001). Endowment effects are less intense among more experienced persons (List 2003, 2004). Identifying more experienced buyers as those who buy more expensive cars or live in more expensive homes, we find mixed evidence on the proposition that more experienced buyers are less influenced by sunk costs. Our findings are robust to other specifications of sunk costs and differences in sample, and survive validation and falsification exercises.

Finally, we also test the behavioral model in Hong Kong, a market where cars are expensive but the government does not explicitly impose sunk costs. We find that sunk costs also influence Hong Kong car buyers to drive more.

Overall, our empirical analysis suggests that buyers of cars in Singapore and Hong Kong exhibited a sunk cost fallacy and did not self-correct (or did not fully self-correct) this decision bias. To our knowledge, this is the first field evidence of the sunk cost fallacy in the usage of a major durable good.

In the remainder of this paper, Section 2 describes Singapore government policies on car ownership and usage. Section 3 presents a behavioral model of mental accounting for sunk costs, Section 4 presents the empirical strategy, and Section 5 introduces the data. Section 6 reports reduced-form estimates followed by structural estimates of the behavioral model and extended behavioral model, and Section 7 presents a comparative analysis using Hong Kong data. Section 8 discusses the implications of our findings for policy and management, while Section 9 concludes. The online appendix presents additional estimates that explore heterogeneous effects and alternative specifications and rule out other selection-based explanations.

\section{Singapore Car Policies}

Singapore is a small, densely populated city-state, which, like many other cities, faces the challenge of managing traffic congestion. Since 1975, the Singapore government has tackled traffic congestion in two ways-pricing road usage and limiting the vehicle population. While the government's policies to manage traffic congestion target all vehicles, we focus on cars in the discussion below. Initially, the government sought to limit purchases of cars through a hefty tax, the "Additional Registration Fee" (ARF), on new car registrations. The ARF is based on the wholesale cost or import price of the car, which is officially called the "open market value" (OMV). At the time of writing, the ARF was set at $100 \%$ of OMV. (No cars are manufactured in Singapore. Since all are imported, the import price equals the wholesale cost.)
Beginning in 1990, the Singapore government explicitly limited the number of new car registrations by imposing a quota for a certificate of entitlement (COE). A new car may be registered only with a COE, which is valid for 10 years. The government sets the $\mathrm{COE}$ quota so that the overall car population (net of cars that are deregistered) does not exceed a specified target. Twice a month, the government holds an auction for sale of the COEs. The official name for the price of the COE is the "quota premium," so-called because it arises only if the number of bids for COEs exceeds the quota. There has always been excess demand for the quota, giving rise to a nonnegative COE premium. Accordingly, in Singapore, the buyer of a new car pays

$$
\begin{aligned}
\text { Retail_price }= & {\left[1+\pi_{\mathrm{ARF}}+\pi_{\mathrm{tax}}\right] \cdot \mathrm{OMV}+\mathrm{COE} \_ \text {premium } } \\
& + \text { Retail_markup }
\end{aligned}
$$

where $\pi_{\mathrm{ARF}}$ and $\pi_{\operatorname{tax}}$ represent the rates of ARF and other taxes, respectively.

One result of the Singapore's government policy to limit car ownership is that retail prices of cars are the world's highest. The average price of a car in our sample (what in Europe and the United States would be considered a typically middle-class brand) is $\$ \$ 177,000$ (US\$115,000).

Buyers of new cars incur substantial policy-related sunk costs as a result of the rebate structures of the $\mathrm{ARF}$ and COE. Each COE is valid for 10 years. Once a COE is used to register a new car, it cannot be detached and used for another car. The owner can only deregister the car (and sell it to a scrap dealer or ship it out of Singapore) and then apply to the government for a rebate on the COE.

Within our period of study, the COE policy provided a rebate for deregistration of a car on the following terms. In the first two years of ownership, the rebate is capped at $80 \%$ of the COE premium, and so, $20 \%$ of the COE premium is sunk upon purchase of the car. Thereafter, the rebate is prorated by the days remaining until the car reaches 10 years of age. The COE expires after 10 years, after which the owner must either renew the COE or deregister the car.

Within our period of study, the ARF policy provided a rebate for deregistration of a car on the following terms. In the first five years of ownership, the rebate is capped at $75 \%$ of the ARF, and so, $25 \%$ of the ARF is sunk upon purchase of the car. Thereafter, the rebate is prorated, $5 \%$ stepwise, by the number of years remaining until the car reaches 10 years of age. ${ }^{4}$

Consequently, as Figure 2 illustrates, the purchase of a new car involves two policy-related sunk costs: ${ }^{5}$

- Immediately after purchase, $20 \%$ of the COE premium is sunk. This cost does not vary with usage or age. From the day after the first 24 months, the car 
Figure 2. (Color online) COE and ARF Rebate Structure

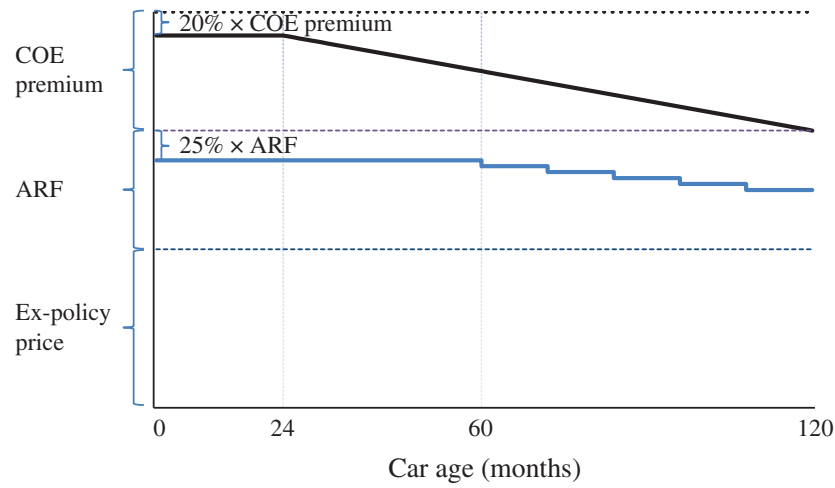

owner forgoes the prorated part of the COE premium each day, a cost that varies with age but not usage.

- Immediately after purchase, $25 \%$ of ARF is sunk. This cost does not vary with usage or age. From the day after the first 60 months, the car owner forgoes $5 \%$ of the ARF each year, a cost that varies with the year but not within the year and not with usage.

These sunk costs vary exogenously over time. Twice a month, the COE premium equilibrates the demand for new cars with quotas for new car registrations. Recall that the quota is fixed according to a specific formula. With changes in demand and quota, the COE premium varies, and so, the COE-related sunk cost of a new car purchase would vary.

The ARF and ARF-related sunk costs also fluctuate over time. Since the ARF is specified as a percentage of the OMV, any change in OMV as a result of changes in exchange rates or the manufacturer's wholesale pricing would affect the ARF and, therefore, the ARF-related sunk cost. Moreover, within a single brand, the ARFs on the various models differ according to the differences in their respective OMVs.

We define the policy-related sunk cost as the sum of COE premium*related and ARF-related sunk costs. As Figure 3 shows, there is substantial variation in the policy-related sunk cost, both cross-sectionally (due to differences in the ARF among cars with different wholesale cost) and over time (due to fluctuations in COE premia and changes in ARF rates). The standard deviation of the policy-related sunk cost is $\$ \$ 3,993$ compared with the mean of $\mathbf{\$} \$ 17,154$. We exploit this variation to identify the effect of sunk costs on car usage.

To better understand the policy background, Table 1 , column (a) reports a regression of the monthly COE premium on the COE quota, measures of driving costs, and macroeconomic factors. The statistically significant variables are the COE quota and macroeconomic factors (quarter and year fixed effects, not reported for brevity). The coefficient of congestion, as measured by the number of cars per kilometer of road, is negative
Figure 3. (Color online) Policy-Related Sunk Costs

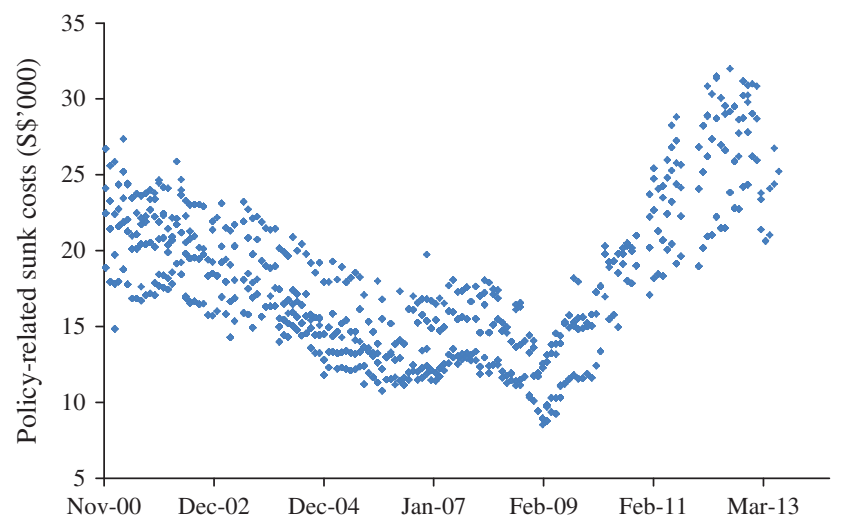

Notes. For all cars in the sample (8,264 cars). Average policy-related sunk cost in the sample is $\$ \$ 17,154$, with a standard deviation of S\$3,993.

but not precisely estimated. As an additional check, Table 1, column (b) reports a regression of the change (first difference) in the COE premium on the changes in the various factors. Among the explanatory variables, only the change in the COE quota is (marginally) significant. These results suggest that changes in COE premia are primarily the result of exogenous factors beyond the control of individual drivers. ${ }^{6}$

Table 1. COE Premium

(a) (b)

\begin{tabular}{lcc} 
Variable & COE premium & Change in COE premium \\
\hline Constant & $163.856^{*}$ & 0.369 \\
& $(87.964)$ & $(0.470)$ \\
COE quota (000's) & $-4.667^{* * *}$ & \\
& $(1.020)$ & $-2.088^{*}$ \\
Change in COE quota & & $(1.249)$ \\
& & \\
CPI fuel index & -0.026 & \\
& $(0.115)$ & -0.002 \\
Change in CPI fuel index & & $(0.144)$ \\
& & \\
Cars per km & $-1.780^{*}$ & \\
& $(0.991)$ & $(1.246)$ \\
Change in cars per km & & \\
& & \\
Quarterly GDP & $0.800^{*}$ & 0.530 \\
& $(0.432)$ & $(0.409)$ \\
Change in quarterly GDP & & No \\
& & No \\
Year fixed effects & Yes & 130 \\
Quarter fixed effects & Yes & 0.04 \\
Observations & 131 & \\
R-squared & 0.953 & \\
\hline
\end{tabular}

Notes. Sample: April 2002-December 2013 (data on COE quota available since April 2002); COE premia are in thousands of Singapore dollars, and GDP are in billions of Singapore dollars. Standard errors are in parentheses.

${ }^{* * * *} p<0.01 ;{ }^{* *} p<0.05 ;{ }^{*} p<0.1$. 


\section{Behavioral Model}

To estimate the impact of sunk costs on car usage and evaluate the corresponding policy implications, we develop a model of driving behavior in the presence of mental accounting. We begin with a model of rational behavior and then extend the model to include mental accounting for sunk cost. The behavioral model nests the rational model as a special case, and as a consequence, we can empirically test whether the data reject the rational model.

\subsection{Rational Behavior}

We focus on individuals who have already bought a car and do not model the decision to buy a car. ${ }^{7}$ Consider an individual who has just bought a car in period 0 . She must decide how many kilometers to drive, $q_{t}$, in each month $t$ over a planning horizon, $1, \ldots, T$. In each month $t$, let the driver's utility be

$$
U\left(q_{t}, t\right)=B\left(q_{t}, t\right)-C\left(q_{t}, t\right)-D\left(q_{t}, t\right),
$$

where $B\left(q_{t}, t\right)$ is the benefit from usage, $C\left(q_{t}, t\right)$ is usage-related costs other than depreciation, and $D\left(q_{t}, t\right)$ is depreciation.

Let the benefit from usage be

$$
B\left(q_{t}\right)=\theta_{0}+\theta_{1} q_{t}-\theta_{2} q_{t}^{2}+\phi(t) q_{t}
$$

or, equivalently, let the marginal benefit from usage be

$$
B^{\prime}\left(q_{t}\right)=\theta_{1}-2 \theta_{2} q_{t}+\phi(t) .
$$

We assume that $\theta_{1}, \theta_{2}>0$, so that the marginal benefit, $B^{\prime}(\cdot)>0$, and the marginal benefit diminishes with usage, $B^{\prime \prime}(\cdot)<0 .{ }^{8}$ The function, $\phi(\cdot)$, represents the effect of time on marginal benefit. The driver's marginal benefit might decline with time for two reasons. One is a taste for novelty-newer cars provide more excitement. The other reason is that older cars break down more frequently and so provide less benefit. Consequently, the marginal benefit diminishes with time (or more precisely, with the age of the car). On the other hand, if the driver needs time to learn about the various features of the car, her marginal benefit might actually increase initially and then decline with time. To allow for both possibilities, we specify that

$$
\phi(t)=\phi_{1} t+\phi_{2} t^{2}
$$

with no restriction on the signs of $\phi_{1}$ and $\phi_{2}$. With regard to the cost of usage other than depreciation, we assume that it comprises the perceived cost of gasoline (petrol) and cost of congestion, both of which increase linearly with usage. Specifically,

$$
C\left(q_{t}, t\right)=\beta_{1} g_{t} q_{t}+\beta_{2} c_{t} q_{t}
$$

where $\beta_{1}, \beta_{2}>0$. On the right-hand side of (6), $\beta_{1} g_{t}$ represents the perceived cost of gasoline per kilometer of usage, where $g_{t}$ is the price, and $\beta_{2} c_{t}$ represents the perceived cost of congestion per kilometer of usage, where we measure $c_{t}$ by the number of cars per kilometer of road.

As for depreciation, referring to the retail price of the car in (1), let

$$
\begin{aligned}
P & =\text { Retail_price }-A R F-C O E \_p r e m i u m \\
& =\left[1+\pi_{\mathrm{tax}}\right] \cdot O M V+\text { Retail_mark-up }
\end{aligned}
$$

represent the "ex-policy price" of the car. We assume that the depreciation of the retail price is additively separable in time and usage. From the rebate structure of the COE and ARF (described in Section 2), we model the depreciation as

$$
\begin{aligned}
D\left(q_{t}, t\right)= & \delta_{0}\left[P-s_{0}\right]+\delta_{1}(t)\left[\text { ARF }-s_{1}\right] \cdot 1(t>60) \\
& +\delta_{2}(t)\left[C O E-s_{2}\right] \cdot 1(t>24)+\delta_{3} q_{t}
\end{aligned}
$$

where $s_{0}, s_{1}$, and $s_{2}$ represent the sunk portions of the ex-policy price, $\mathrm{ARF}$, and COE premium, respectively; $\delta_{0}$ is the depreciation rate of the ex-policy price; $\delta_{1}(t)$ and $\delta_{2}(t)$ are the depreciation functions of the ARF and COE premium, respectively (as given in Figure 2); and $\delta_{3}$ is the rate of depreciation with usage.

Substituting above, the consumer's utility is

$$
\begin{aligned}
U\left(q_{t}, t\right)= & \theta_{0}+\theta_{1} q_{t}-\theta_{2} q_{t}^{2}+\left[\phi_{1} t+\phi_{2} t^{2}\right] q_{t}-\beta_{1} g_{t} q_{t} \\
& -\beta_{2} c_{t} q_{t}-D\left(q_{t}, t\right) .
\end{aligned}
$$

Assuming that the driver is forward-looking, in each month $t$, she chooses usage $q_{t}$ to maximize the cumulative utility of driving, $\Sigma_{\tau=t}^{T} U\left(q_{\tau}, \tau\right)$. Proposition 1 characterizes the optimal usage.

Proposition 1. With rational behavior, the optimal usage in month $t=1, \ldots, T$ is

$$
q_{t}^{*}=\frac{1}{2 \theta_{2}}\left[\left[\theta_{1}-\delta_{3}\right]+\phi_{1} t+\phi_{2} t^{2}-\beta_{1} g_{t}-\beta_{2} c_{t}\right] .
$$

Proof. In each month $t$, the consumer chooses $q_{t}$ to maximize

$$
\begin{aligned}
\sum_{\tau=t}^{T} U\left(q_{\tau}, \tau\right)=\sum_{\tau=t}^{T}[ & \theta_{0}+\theta_{1} q_{\tau}-\theta_{2} q_{\tau}^{2}+\left[\phi_{1} \tau+\phi_{2} \tau^{2}\right] q_{\tau} \\
& \left.-\beta_{1} g_{\tau} q_{\tau}-\beta_{2} c_{\tau} q_{\tau}-D\left(q_{\tau}, \tau\right)\right] .
\end{aligned}
$$

Substituting from (8) and maximizing (11) with respect to $q_{t}$, the optimal usage is given by

$$
2 \theta_{2} q_{t}^{*}=\left[\theta_{1}-\delta_{3}\right]+\phi_{1} t+\phi_{2} t^{2}-\beta_{1} g_{t}-\beta_{2} c_{t},
$$

for all $t$.

By Proposition 1, the optimal usage is independent of the sunk costs, $s_{0}, s_{1}$, and $s_{2}$, related to the ex-policy price, $\mathrm{ARF}$, and COE premium, respectively. It varies with time according to (5) and declines with the costs of gasoline and congestion. 


\subsection{Mental Accounting for Sunk Costs}

Next, we generalize the model to allow for the sunk cost fallacy. Suppose that the driver's utility in month $t$ depends on both usage and mental accounting for the sunk cost in the following way:

$$
\begin{aligned}
& U\left(Q_{t}, q_{t}, t\right) \\
& = \begin{cases}B\left(q_{t}\right)-C\left(q_{t}, t\right)-D\left(q_{t}, t\right)-M\left(S, Q_{t}\right) & \text { if } t \leq T_{S}, \\
B\left(q_{t}\right)-C\left(q_{t}, t\right)-D\left(q_{t}, t\right) & \text { if } t>T_{S} .\end{cases}
\end{aligned}
$$

Within the horizon $t \leq T_{S}$, (13) differs from the model of rational behavior by the additional term $M\left(S, Q_{t}\right)$, which represents the psychological disutility of carrying a mental account of the sunk cost $S$ and cumulative mileage $Q_{t}$.

Gourville and Soman (1998) and Thaler (1999) find that sunk costs are salient and influence behavior, with diminishing effect, over a finite period. Accordingly, we stipulate that the mental accounting lasts for some finite horizon, $T_{S}$. Beyond the horizon, for $t>T_{S}$, the sunk cost is sufficiently remote such that it does not affect the driver, and so, her usage follows the rational model.

Referring to Section 2 and Figure 2, the structure of Singapore government policies suggests that the mental accounting horizon might range between 24 and 60 months. With regard to the COE premium, 20\% is nonrefundable, while the refundable part declines on a daily basis from the third until the 10th year. So the nonrefundable sunk part of the COE premium is similar to a lump sum payment for two years, which suggests that drivers might carry a mental account for 24 months. As for the ARF, $25 \%$ is nonrefundable, while the refundable part declines in steps of $5 \%$ each year from the 6th until the 10th year. So the nonrefundable sunk part of the ARF is similar to paying a lump sum for five years, which suggests that drivers might carry a mental account for 60 months.

We stipulate that the psychological disutility is well behaved in the following sense: $M\left(S, Q_{t}\right)$ decreases in $Q_{t}$, with $\lim _{t \rightarrow T_{S}} M\left(S, Q_{t}\right)=0$. Under this assumption, the psychological disutility of carrying the mental account diminishes with cumulative usage. Intuitively, as the driver accumulates usage, the sunk cost becomes less salient and its psychological effect wears off.

To maintain analytical tractability without loss of generality, we specify the psychological disutility as a linear function of cumulative mileage, sunk cost, and their interaction:

$$
M\left(S, Q_{t}\right)=\lambda_{1}+\lambda_{2} Q_{t}+\lambda_{3} S+\lambda_{4} S \cdot Q_{t} .
$$

Substituting from (3), (5), (6), (8), and (14) in (13), the driver's utility within the mental accounting horizon, $T_{S}$, simplifies to

$$
\begin{aligned}
& U\left(Q_{t}, q_{t}, t\right) \\
& \quad=\theta_{0}+\theta_{1} q_{t}-\theta_{2} q_{t}^{2}+\left[\phi_{1} t+\phi_{2} t^{2}\right] q_{t}-\beta_{1} g_{t} q_{t}-\beta_{2} c_{t} q_{t}
\end{aligned}
$$

$$
\begin{gathered}
-\left[\delta_{0}\left[P-s_{0}\right]+\delta_{1}(t)\left[A R F-s_{1}\right] \cdot 1(t>60)\right. \\
\left.+\delta_{2}(t)\left[C O E-s_{2}\right] \cdot 1(t>24)+\delta_{3} q_{t}\right] \\
-\left[\lambda_{1}+\lambda_{2} Q_{t}+\lambda_{3} S+\lambda_{4} S \cdot Q_{t}\right] .
\end{gathered}
$$

Assume that the driver is forward-looking and, in each month $t$, chooses usage $q_{t}$ to maximize $U_{t} \equiv$ $\sum_{\tau=t}^{T_{S}} U\left(Q_{\tau}, q_{\tau}, \tau\right)$. The driver accounts for the effect of $q_{t}$ on future utility through the cumulative usage up to month $t, Q_{t}=\sum_{\tau=1}^{t} q_{\tau}$. Within the horizon, $T_{S}$, we characterize the driver's usage in the last month, $q_{T_{S}}^{*}$, and then work backward, solving for $q_{T_{S}-1}^{*}$, etc. Specifically, for each $t=T_{S}, T_{S}-1, \ldots, 2,1$, differentiate $U_{t}$ with respect to $q_{t}$ to obtain the first-order condition.

Differentiating the cumulative expected utility for $t=T_{S}$,

$$
\begin{aligned}
\frac{d U_{T_{S}}}{d q_{T_{S}}}= & \frac{d U\left(Q_{T_{S}}, q_{T_{S}}, T_{S}\right)}{d q_{T_{S}}} \\
= & {\left[\theta_{1}-\delta_{3}\right]-2 \theta_{2} q_{T_{S}}+\phi_{1} T_{S}+\phi_{2} T_{S}^{2} } \\
& -\beta_{1} g_{T_{S}}-\beta_{2} c_{T_{S}}-\lambda_{2}-\lambda_{4} S=0
\end{aligned}
$$

and hence,

$$
\begin{gathered}
q_{T_{S}}^{*}=\frac{1}{2 \theta_{2}}\left\{\left[\theta_{1}-\delta_{3}\right]+\phi_{1} T_{S}+\phi_{2} T_{S}^{2}-\beta_{1} g_{T_{S}}-\beta_{2} \mathcal{C}_{T_{S}}\right. \\
\left.-\lambda_{2}-\lambda_{4} S\right\} .
\end{gathered}
$$

Similarly, differentiating the cumulative expected utility for $t=T_{S}-1$ and simplifying the terms,

$$
\begin{aligned}
\frac{d U_{T_{S}-1}}{d q_{T_{S}-1}}= & \frac{d U\left(Q_{T_{S}}, q_{T_{S}}, T_{S}\right)}{d q_{T_{S}-1}}+\frac{d U\left(Q_{T_{S}-1}, q_{T_{S}-1}, T_{S}-1\right)}{d q_{T_{S}-1}} \\
= & {\left[\theta_{1}-\delta_{3}\right]-2 \theta_{2} q_{T_{S}-1}+\phi_{1}\left[T_{S}-1\right]+\phi_{2}\left[T_{S}-1\right]^{2} } \\
& -\beta_{1} g_{T_{S}-1}-\beta_{2} c_{T_{S}-1}-2 \lambda_{2}-2 \lambda_{4} S=0,
\end{aligned}
$$

which yields

$$
\begin{array}{r}
q_{T_{S}-1}^{*}=\frac{1}{2 \theta_{2}}\left\{\left[\theta_{1}-\delta_{3}\right]+\phi_{1}\left[T_{S}-1\right]+\phi_{2}\left[T_{S}-1\right]^{2}\right. \\
\left.-\beta_{1} g_{T_{S}-1}-\beta_{2} c_{T_{S}-1}-2 \lambda_{2}-2 \lambda_{4} S\right\} .
\end{array}
$$

Reasoning recursively, we can show that the optimal usage in months $t=1, \ldots, T_{S}$ is

$$
\begin{array}{r}
q_{t}^{*}=\frac{1}{2 \theta_{2}}\left\{\left[\theta_{1}-\delta_{3}\right]+\phi_{1} t+\phi_{2} t^{2}-\beta_{1} g_{t}-\beta_{2} c_{t}\right. \\
\left.-\lambda_{2}\left[T_{S}-t+1\right]-\lambda_{4}\left[T_{S}-t+1\right] S\right\} .
\end{array}
$$

For months $t=T_{S}+1, \ldots, T$, the optimal usage is characterized by the rational model (10). Accordingly, we have the following.

Proposition 2. With mental accounting for sunk costs, the driver chooses usage,

$$
q_{t}^{*}= \begin{cases}\frac{1}{2 \theta_{2}}\left\{\left[\theta_{1}-\delta_{3}\right]+\phi_{1} t+\phi_{2} t^{2}-\beta_{1} g_{t}-\beta_{2} c_{t}\right. & \\ \left.-\lambda_{2}\left[T_{S}-t+1\right]-\lambda_{4} S\left[T_{S}-t+1\right]\right\} & \text { if } t \leq T_{S}, \\ \frac{1}{2 \theta_{2}}\left\{\left[\theta_{1}-\delta_{3}\right]+\phi_{1} t+\phi_{2} t^{2}-\beta_{1} g_{t}-\beta_{2} c_{t}\right\} & \text { if } t>T_{S} .\end{cases}
$$


Notice that if $\lambda_{2}=\lambda_{4}=0$, then (17) simplifies to (10). Hence, the model of mental accounting nests rational behavior as a special case.

To characterize the implications of mental accounting for sunk costs on usage, consider the marginal effect of the sunk cost on the driver's choice of usage. Differentiating (17) with respect to $S$,

$$
\frac{d q_{t}^{*}}{d S}=-\lambda_{4}\left[T_{S}-t+1\right]
$$

for $t \leq T_{S}$.

If $\lambda_{4}<0$, then the empirical implication of mental accounting for sunk costs is higher usage at all times, to an extent that diminishes linearly with time. If $\lambda_{4}=0$, then $d q_{t}^{*} / d S=0$, and the mental accounting for sunk costs has no effect on usage. By contrast, if $\lambda_{4}>0$, then the empirical implication is lower usage that rises over time. Thus we have the following corollary.

Corollary 1. With mental accounting for sunk costs, the driver chooses usage $q_{t}^{*}$ in months $t=1, \ldots T_{S}$ that

(a) if $\lambda_{4}<0$, increases in the sunk cost and attenuates over time at a rate that increases in the sunk cost, or

(b) if $\lambda_{4}>0$, decreases in the sunk cost and rises over time at a rate that increases in the sunk cost.

The behavioral model of mental accounting encompasses two very different theories of how sunk costs influence the driver's behavior. Under one theory $\left(\lambda_{4}<0\right)$, the driver amortizes the burden of the sunk cost by the accumulated usage. At each point in time, the more the driver has used the car up to then, the smaller the mental burden of the sunk cost. Under an alternative theory $\left(\lambda_{4}>0\right)$, the driver wants to stretch out the use of the car over the mental accounting horizon. Intuitively, the more she has used the car, the larger the mental burden of the sunk cost.

Figure 4 illustrates the difference in the trajectory of usage with and without mental accounting. Assume that the costs of gasoline and congestion, $g_{t}, c_{t}$, are constant and that there is no time (age)-dependent marginal benefit, $\phi_{1}=\phi_{2}=0$. Then, with rational behavior, the monthly usage would be constant throughout.

By contrast, comparing (17) with (10), mental accounting for sunk costs can affect usage within the mental accounting horizon in two ways. If $\lambda_{4}<0$, then a larger sunk cost would be associated with higher usage and faster attenuation. By contrast, if $\lambda_{4}>0$, then a larger sunk cost would be associated with lower usage and faster appreciation.

The effect of the sunk cost on the rate of change of usage over the mental accounting horizon is the essence of our empirical strategy. This effect on the rate of change of usage distinguishes the model of mental accounting for sunk costs from the most obvious alternative explanation of any empirical relation
Figure 4. (Color online) Effect of Mental Accounting for Sunk Costs on Car Usage

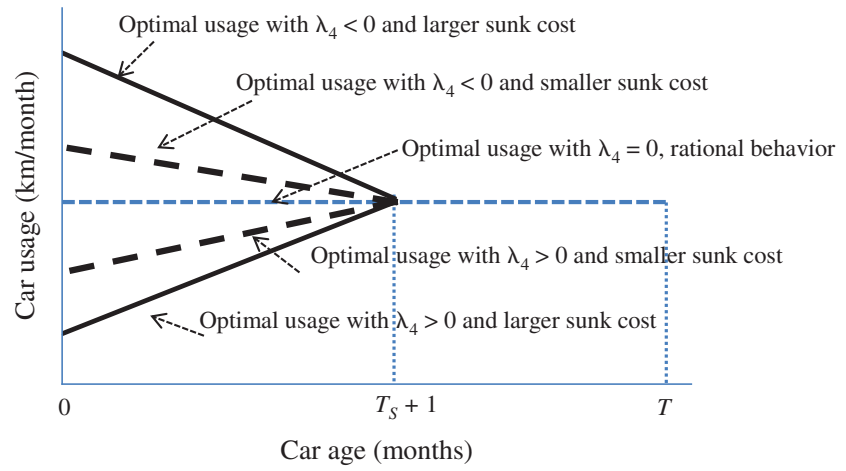

Notes. Monthly car usage assuming cost of gasoline and congestion fixed over time and no time (age)-dependent marginal benefit.

between usage and sunk costs, which is selection (called "screening" by Ashraf et al. 2010). Selection causes higher sunk costs to be associated with higher usage in the following way. When COE premia and ARF are higher, the prices of new cars are higher. With the increase in price, people who plan to drive less would be less likely to buy cars; thus, the population of car owners would comprise relatively more intensive drivers. An increase in usage with respect to the price of the car may be associated with mental accounting for sunk costs or with selection. However, it is challenging to explain the rate of attenuation or appreciation of driving by selection. By contrast, our behavioral model specifically implies that, with mental accounting for sunk costs, the effect of the sunk cost should attenuate or increase over time and therefore affect the rate at which driving attenuates or rises over time. ${ }^{9}$

By Corollary 1, if $\lambda_{4}<0$, the effect of the sunk cost attenuates over time. The essential reason is the structure of the mental accounting. Referring to (14), in each month, as the driver looks forward, the mental burden of the sunk cost is reduced by the cumulative usage. In the earlier months, the weight of the mental account is large, and therefore the impact on usage is large. By contrast, closer to the terminal month, the mental burden is smaller, and the impact on usage diminishes. Accordingly, it is optimal for the driver to use the car relatively more in the earlier months to the extent that the sunk cost is larger. This provides us with a clear, empirically testable parameter restriction.

This theoretical implication is consistent with two previous empirical studies. In the experiment by Arkes and Blumer (1985), consumers who paid a higher price for the season ticket attended more shows in the first half of the season, but not in the second half. Gourville and Soman (1998) monitored attendance at an athletic facility by members who paid for a one-year membership in two semiannual installments. Members visited the facility most during the month of paying the installment, and their visits declined with each succeeding 
month. Both studies found that the sunk cost fallacy affected behavior only for a finite period of time.

\section{Empirical Strategy}

To set up the econometric model for structural estimation, let the actual usage of individual driver $i$ in month $t$ (or more precisely, the age of the car in months) be $q_{i t}=q_{i t}^{*}+\epsilon_{i t}$, where $\epsilon_{i t}$ is an error. Substituting from (17) for $q_{i t}^{*}$ and assuming $\theta_{2}=\frac{1}{2}$,

$$
\begin{aligned}
q_{i t}= & {\left[\theta_{1}-\delta_{3}\right]-\lambda_{2}\left[T_{S}-t+1\right] \cdot 1_{t \leq T_{S}}+\phi_{1} t+\phi_{2} t^{2} } \\
& -\beta_{1} g_{t}-\beta_{2} c_{t}-\lambda_{4}\left[T_{S}-t+1\right] S_{i} \cdot 1_{t \leq T_{S}}+\epsilon_{i t}
\end{aligned}
$$

for $i=1, \ldots, N$.

Assume that the error, $\epsilon_{i t}$, comprises two elements,

$$
\epsilon_{i t}=\xi_{i}+v_{i t}
$$

where $v_{i t}$ is pure individual and time-specific idiosyncratic error and $\xi_{i}$ is an individual fixed effect that captures all unobservable time-invariant attributes of the owner that may influence usage. The individual fixed effect abstracts from differences including selection by driving intensity-for instance, when higher car prices selectively screen out those who plan to drive less intensively. The individual fixed effect also abstracts from changes in the composition of buyers over time. Furthermore, the individual fixed effect abstracts from differences between first and second cars. Two-car households would drive each car less than one-car households. ${ }^{10}$

Our data on car usage are based on periodic services of each car at irregular time intervals. To apply the econometric model, we organize the data as monthly averages between service visits. Suppose that car $i$ was serviced in months, $t_{i r}$, where $r=1,2, \ldots, R$, and $t_{i 0}=0$. Then, define the interservice average of usage,

$$
q_{i r} \equiv \frac{1}{t_{i r}-t_{i, r-1}} \sum_{\tau=t_{i, r-1}+1}^{t_{i r}} q_{i \tau}
$$

the interservice average of the remaining horizon, the interservice average of the age of the car, and the interservice average of the square of the car age, respectively:

$$
\begin{aligned}
m_{1, i r} & \equiv \frac{1}{t_{i r}-t_{i, r-1}} \sum_{\tau=t_{i, r-1}+1}^{t_{i r}}\left[T_{S}-\tau+1\right] \cdot 1\left[\tau \leq T_{S}\right], \\
m_{2, i r} & \equiv \frac{1}{t_{i r}-t_{i, r-1}} \sum_{\tau=t_{i, r-1}+1}^{t_{i r}} \tau, \\
z_{i r} & \equiv \frac{1}{t_{i r}-t_{i, r-1}} \sum_{\tau=t_{i, r-1}+1}^{t_{i r}} \tau^{2} .
\end{aligned}
$$

Likewise, define the interservice averages of the cost of petrol, congestion, and idiosyncratic error, respectively:

$$
\begin{aligned}
g_{i r} & \equiv \frac{1}{t_{i r}-t_{i, r-1}} \sum_{\tau=t_{i, r-1}+1}^{t_{i r}} g_{\tau}, \\
c_{i r} & \equiv \frac{1}{t_{i r}-t_{i, r-1}} \sum_{\tau=t_{i, r-1}+1}^{t_{i r}} c_{\tau}, \\
v_{i r} & \equiv \frac{1}{t_{i r}-t_{i, r-1}} \sum_{\tau=t_{i, r-1}+1}^{t_{i r}} v_{i \tau} .
\end{aligned}
$$

Substituting the above and (20) in (19),

$$
\begin{aligned}
q_{i r}= & {\left[\theta_{1}-\delta_{3}\right]-\lambda_{2} m_{1, i r}+\phi_{1} m_{2, i r}+\phi_{2} z_{i r}-\beta_{1} g_{i r} } \\
& -\beta_{2} c_{i r}-\lambda_{4} S_{i} m_{1, i r}+\xi_{i}+v_{i r}
\end{aligned}
$$

for $r=1,2, \ldots, R$. To abstract from the individual fixed effect, we recast the model in first differences, which yields the following estimation model:

$$
\begin{aligned}
\Delta q_{i r}= & -\lambda_{2} \Delta m_{1, i r}+\phi_{1} \Delta m_{2, i r}+\phi_{2} \Delta z_{i r}-\beta_{1} \Delta g_{i r} \\
& -\beta_{2} \Delta c_{i r}-\lambda_{4} S_{i} \Delta m_{1, i r}+\Delta v_{i r}
\end{aligned}
$$

where $\Delta q_{i r} \equiv q_{i r}-q_{i, r-1}, \Delta m_{1, i r} \equiv m_{1, i r}-m_{1, i, r-1}, \Delta m_{2, i r} \equiv$ $m_{2, i r}-m_{2, i, r-1}, \Delta z_{i r} \equiv z_{i r}-z_{i, r-1}, \Delta g_{i r} \equiv g_{i r}-g_{i, r-1}, \Delta c_{i r} \equiv$ $c_{i r}-c_{i, r-1}$ and $\Delta v_{i r} \equiv v_{i r}-v_{i, r-1}$.

\section{Data}

Our primary source of data is the sole authorized dealer for a midmarket brand of cars in Singapore. The dealer provided the complete service records of all new cars sold between 2000 and 2013 under a nondisclosure agreement for this study. The cars are different models of the same brand.

Owners bring their cars to the authorized dealer for maintenance service. The service records for each car include the date of registration, engine size, service dates, and odometer readings. To protect customer privacy, the dealer did not provide any demographic information on the car buyers.

In our sample, the maximum observed age is 119 months, which is less than the lifespan of a COE (120 months). ${ }^{11}$ To exclude outliers, we further limit the sample to cars with usage within two standard deviations of the logarithm of the average monthly usage. After cleaning for obvious recording errors (mainly cars with odometer readings that decreased over time), excluding cars that were defective (identified by premature service visits), and excluding cars with fewer than two service records, the final sample comprises 8,264 cars with 45,195 service visits.

The cars were purchased at different times, and the owners perform maintenance at varying intervals; thus, the cars have different numbers of service visits. 
Table 2. Summary Statistics

\begin{tabular}{llcccc}
\hline Variable & \multicolumn{1}{c}{ Unit } & Mean & s.d. & Min & Max \\
\hline Usage & 1,000 kilometers per month & 1.545 & 0.529 & 0.539 & 4.189 \\
Age of car at last service & Months & 49.2 & 21.9 & 5 & 119 \\
Retail price & S\$ million & 0.177 & 0.031 & 0.110 & 0.317 \\
ARF & S\$ million & 0.047 & 0.009 & 0.031 & 0.092 \\
COE premium & S\$ million & 0.027 & 0.016 & 0.001 & 0.096 \\
Policy-related sunk costs & S\$ million & 0.017 & 0.004 & 0.009 & 0.032 \\
Relative policy-related sunk costs & S\$ million & 0.020 & 0.006 & 0.005 & 0.078 \\
Gasoline price & January 2006 = 100 & 106.64 & 16.80 & 69.10 & 130.82 \\
Congestion & Cars per kilometer & 99.27 & 7.47 & 82.85 & 106.33 \\
\hline
\end{tabular}

Notes. As of January 1, 2007, US $\$ 1=$ S $\$ 1.54$. Policy-related sunk costs is the sum of COE- and ARF-related sunk costs; Relative policy-related sunk costs is the policy-related sunk costs divided by the CPI-adjusted average price per square meter in units of Singapore thousands of dollars.

Accordingly, the data constitute an unbalanced panel of cars with average monthly usage ranging between 539 and 4,189 kilometers (or, equivalently, annual usage ranging between 4,042 and 31,418 miles). ${ }^{12}$

Our next source of data is the Land Transport Authority (LTA). The LTA collects and publishes the retail price, $\mathrm{OMV}, \mathrm{ARF}$, and $\mathrm{COE}$ for each brand and model of car on a monthly basis. We match this information by month and engine size to the registration of each car. In addition, to estimate the extension of the behavioral model to relative sunk costs, the LTA provided us with the address of car buyers by postal sector and date of registration (Singapore is divided into 90 postal sectors). We match this information by engine size and date of registration to each car. To proxy for the income of car buyers, we collect the prices of all high-rise residential property purchases between 2000 and 2013 from the Urban Redevelopment Authority. For each postal sector and year, we compute the average price per square meter of high-rise homes adjusted for inflation by the Consumer Price Index (CPI). To represent the price of gasoline, we use the CPI of 98 octane petrol, and to represent traffic congestion, we use the number of cars (published monthly) divided by the quantity of road space in kilometers (published annually).

Table 2 reports summary statistics of the data. The average monthly usage in the sample is 1,545 kilometers. The retail price of the cars ranges between $S \$ 110,000$ and $\$ \$ 317,000$ with an average of $\$ \$ 177,000$, while the average ARF and COE premium are $S \$ 47,000$ and $S \$ 27,000$, respectively. So, the ARF and COE contribute about $42 \%$ of the retail price. Importantly, the policy-related sunk costs, defined as the sum of the COE- and ARF-related sunk costs, ranges between $S \$ 9,000$ and $\$ \$ 32,000$, with an average of $S \$ 17,000$ (equivalent to US\$11,000). The relative policy-related sunk cost, defined as the policy-related sunk costs divided by the CPI-adjusted average price per square meter of high-rise homes, ranges between $\$ \$ 5,000$ and $S \$ 78,000$, with an average of $S \$ 20,000 .{ }^{13}$

\section{Results}

Our behavioral model (Corollary 1) predicts that, if $\lambda_{4}<0$, then optimal usage attenuates over time. Figure 1 provides some coarse evidence of such attenuation, which is consistent with mental accounting for sunk costs, in a way that the mental burden diminishes with cumulative usage.

To further explore the data, we carry out some reduced-form analyses. Figure 5 presents locally weighted polynomial regressions of cumulative usage up to three, four, and five years on the retail price and policy-related sunk costs. Panel (A) suggests that cumulative usage and retail price tended to covary, but the relation is not monotone. By contrast, in panel (B), there seems to be a clear monotone relation between cumulative usage and the policy-related sunk cost.

Next, we use least squares to regress the average monthly usage between successive service visits on the retail car price and sunk costs. Figure 5 suggests that the effects of price and sunk costs might vary with the age of the car. Accordingly, we include interactions between price and sunk costs and age of car as additional explanatory variables.

Table 3 reports the estimates. Column (a) shows that average monthly usage is not associated with retail price. Column (b) shows that the coefficient of the policy-related sunk costs is positive but not precisely estimated, and the coefficient of the policy-related sunk costs interacted with the age of car is negative and significant. Apparently, higher policy-related sunk costs are associated with more driving and faster attenuation with age of the car. Next, column (c) distinguishes the COE-related from the ARF-related sunk costs. The estimate suggests that driving is related to the $\mathrm{COE}$ but not the ARF.

Overall, the evidence presented in Figure 5 and Table 3 is consistent with our behavioral model of mental accounting-specifically, Corollary 1 with $\lambda_{4}<0$. The sunk cost of purchase is associated with more driving, and driving attenuates at a rate that increases with the policy-related sunk costs and, in particular, the part related to the COE premium. 
Figure 5. (Color online) Cumulative Usage, Retail Car Price, and Policy-Related Sunk Costs

(A)

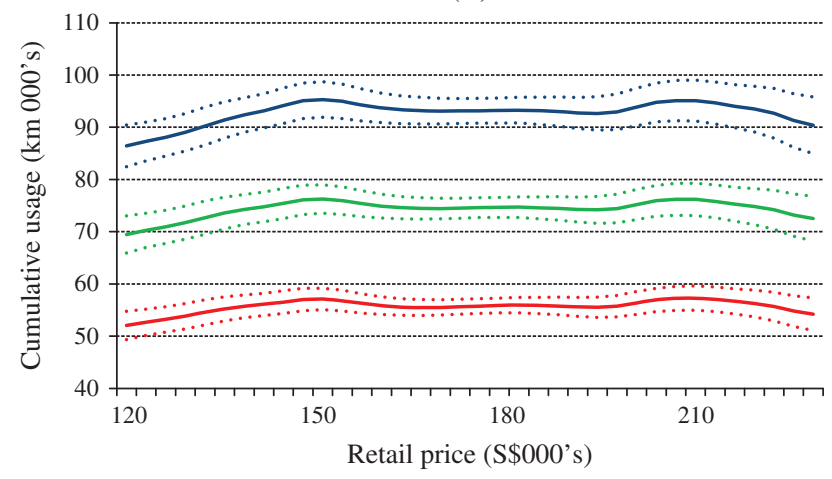

(B)

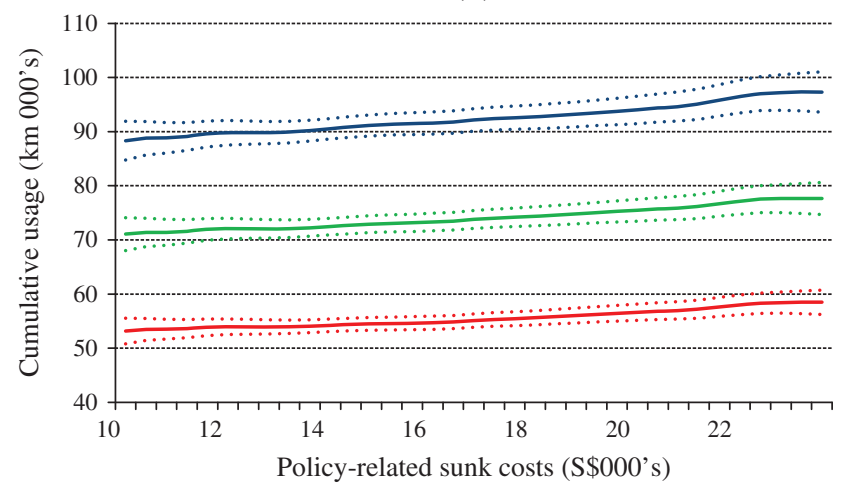

Notes. For the entire sample $(8,264$ cars). Regression graphs and standard errors are generated using a locally weighted polynomial regression. The dashed curves represent the upper and lower bounds of the 95\% confidence interval. Panel (A) depicts regressions of cumulative usage up to three years (lower graph), four years (middle graph), and five years (upper graph) on retail price (in thousands of Singapore dollars). Panel (B) depicts regressions of cumulative usage up to three years (lower graph), four years (middle graph), and five years (upper graph) on the policy-related sunk costs (in thousands of Singapore dollars).

While suggestive of the sunk cost fallacy, Figure 5 and Table 3 are reduced-form analyses that do not allow counterfactual policy and managerial analyses. Accordingly, we now turn to structural estimation of the behavioral model, (25). Although the data set comprises 45,195 service records, after first-differencing, the estimation sample comprises 36,931 observations.

First, to provide a point of reference, we estimate the rational model, i.e., assuming that $\lambda_{2}=\lambda_{4}=0$. Estimates of this model are reported in Table 4 , column (a). The coefficient of the perceived price of gasoline, $\beta_{1}$, is positive and significant. This is consistent with the intuition that higher fuel cost decreases usage. The coefficient of the perceived cost of congestion, $\beta_{2}$, is positive and also significant. ${ }^{14}$ Regarding the effect of car age on usage, $\phi_{1}$ is positive and significant, while $\phi_{2}$ is negative and significant. The estimated coefficients suggest that the effect of "novelty" is to increase usage over the first 66 months and decrease thereafter.

Next, we turn to estimate the behavioral model. Recall from (7) that the retail price comprises the expolicy price, COE premium, and ARF. By government design (see Figure 2), elements of the COE premium and ARF are sunk according to specified schedules. Furthermore, just as in any other car market, part of the ex-policy price may be sunk. Accordingly, we generalize (25) to distinguish the policy-related sunk costs, with coefficient $\lambda_{41}$, and the ex-policy price, with coefficient $\lambda_{42}$.

Another issue is the length of the mental accounting horizon. Above, in developing the behavioral model, we inferred from the structure of the COE and ARF refunds that the mental accounting horizon might range between 24 and 60 months. Accordingly, Table 4 reports structural estimates of the behavioral model at various horizons.

The estimates for 24- to 72-month horizons are consistent in several ways-the coefficients of the perceived costs of gasoline and congestion are positive and significant, the coefficients of age and age squared are positive and negative, respectively, and both are significant. The coefficient of the policy-related sunk costs is negative and precisely estimated, and interestingly, the magnitude of the coefficient declines with the length of the horizon. The ex-policy price is not significant.

Recall that the rational model is the model of mental accounting subject to the restriction that the coefficients of the sunk costs and the remaining horizon are zero; $\lambda_{2}=\lambda_{41}=\lambda_{42}=0$. Table 4 reports F-tests of these restrictions. Across all horizons, the $F$-statistics suggest rejection of the null hypothesis that $\lambda_{2}=\lambda_{41}=$ $\lambda_{42}=0$. Apparently, the mental accounting parameters are significant.

The general picture is that, empirically, driving was sensitive to gasoline prices, congestion, and novelty, and-most important-it was sensitive to sunk costs within a mental accounting horizon of 24 to 72 months. Referring to Corollary 1, our results are consistent with $\lambda_{4}<0$ and a trajectory of higher-than-rational usage that attenuates at a rate that increases with the sunk cost. Our results suggest that car buyers did mentally account for the sunk elements of the ARF and COE premium.

Among the alternative horizons, we prefer 48 months (see Table 4, column (d)). This fits between the horizons of 24 to 60 months that we intuitively expect from the structure of the COE and ARF rebates. Statistically, this specification yields the best fit (largest $R$-squared and (natural) log likelihood).

With a 48-month mental accounting horizon, the coefficient of the mental accounting of the policyrelated sunk costs, $\lambda_{41}=-0.177$ (s.e. 0.058), is negative and precisely estimated. To interpret this coefficient, 
Table 3. Sunk Cost and Car Usage: Reduced-Form Estimates

\begin{tabular}{|c|c|c|c|}
\hline & $\begin{array}{l}\text { (a) } \\
\text { Price }\end{array}$ & $\begin{array}{l}\text { (b) } \\
\text { Policy-related } \\
\text { sunk costs }\end{array}$ & $\begin{array}{l}\text { (c) } \\
\text { Separate COE/ARF } \\
\text { sunk costs }\end{array}$ \\
\hline Price & $\begin{array}{c}-0.098 \\
(0.814)\end{array}$ & & \\
\hline Price $\times$ Average age & $\begin{array}{c}0.006 \\
(0.021)\end{array}$ & & \\
\hline Policy-related sunk costs & & $\begin{array}{l}12.567^{*} \\
(7.054)\end{array}$ & \\
\hline Policy-related sunk costs $\times$ Average age & & $\begin{array}{l}-0.655^{* * *} \\
(0.220)\end{array}$ & \\
\hline COE-related sunk cost & & & $\begin{array}{r}17.822^{*} \\
(9.233)\end{array}$ \\
\hline COE-related sunk cost $\times$ Average age & & & $\begin{array}{l}-0.892^{* * *} \\
(0.345)\end{array}$ \\
\hline ARF-related sunk cost & & & $\begin{array}{c}3.942 \\
(14.845)\end{array}$ \\
\hline ARF-related sunk cost $\times$ Average age & & & $\begin{array}{c}-0.396 \\
(0.350)\end{array}$ \\
\hline $\begin{array}{l}\text { Year fixed effects } \\
\text { Engine size fixed effects }\end{array}$ & $\begin{array}{l}\text { Yes } \\
\text { Yes }\end{array}$ & $\begin{array}{l}\text { Yes } \\
\text { Yes }\end{array}$ & $\begin{array}{l}\text { Yes } \\
\text { Yes }\end{array}$ \\
\hline $\begin{array}{l}\text { Observations } \\
R \text {-squared } \\
\text { ln likelihood } \\
F \text {-statistic } \\
p \text {-value }\end{array}$ & $\begin{array}{c}8,264 \\
0.045 \\
-6,287 \\
0.000 \\
1.000\end{array}$ & $\begin{array}{l}8,264 \\
0.046 \\
-6,281 \\
2.788 \\
0.025\end{array}$ & $\begin{array}{c}8,264 \\
0.046 \\
-6,281 \\
2.479 \\
0.021\end{array}$ \\
\hline
\end{tabular}

Notes. Estimated using ordinary least squares. The dependent variable is average monthly usage (in thousands of kilometers per month) until the last service. Price and sunk costs are in millions of Singapore dollars. Robust standard errors are in parentheses.

${ }_{* * *}^{*} p<0.01 ;{ }^{* *} p<0.05 ;{ }^{*} p<0.1$.

we compute the elasticity of usage with respect to the sunk cost as being 0.048 (s.e. 0.016). ${ }^{15}$ To gauge the significance of this estimate, consider the increase in the average policy-related sunk cost by $\mathrm{S} \$ 13,038$ from $\mathrm{S} \$ 11,278$ to $\mathrm{S} \$ 24,316$ (equivalently, by $116 \%$ ) between January 2009 and January 2013, mainly as a result of an increase in COE premium. Using our estimated elasticity, this increase in sunk cost would be associated with an increase in usage by $5.6 \%$, or 86 kilometers a month. ${ }^{16}$

We believe that the actual effect of the sunk cost exceeds this estimate. Drivers would respond to the sunk cost by varying their discretionary driving (their nondiscretionary driving, commuting to work and sending children to school, for example, would respond less). The effect of the sunk cost would be larger if it were expressed as a proportion of the discretionary driving. Moreover, our estimate of the effect of sunk cost on car usage did not control for income effects. An increase in the COE or ARF would reduce the buyer's discretionary income and so lead to a reduction in all consumption, including driving (Thaler 1980, pp.49-50). Accordingly, our estimate of the sunk cost effect is conservative. ${ }^{17}$

\subsection{Relative Sunk Costs}

Intuitively, a sunk cost of $S \$ 17,000$ (US\$11,000) would loom much larger for a middle-income buyer than for one of the top $1 \%$. Hence, the effect of sunk costs on driving might depend on the buyer's income, with a larger effect among buyers with lower incomes. This motivates us to estimate the behavioral model, (25), with sunk costs specified relative to buyer income. The model of relative sunk cost is interesting as such, and also as a way to identify the effect of sunk costs by variation on another dimension-buyer's income.

Lacking data on buyers' incomes, we use the unit price of housing in their residential neighborhood, specifically the postal sector, as a proxy. We then specify relative policy-related sunk costs as the ratio of the policy-related sunk costs to the CPI-adjusted price per square meter of high-rise homes in each postal sector. The sample is somewhat smaller as service records for some cars could not be matched with the buyer's neighborhood. Table 5 reports the estimates of the rational model and the behavioral model for horizons of 24 to 72 months.

The coefficients of the gasoline price, congestion, age, and age squared are quite similar to those in Table 4, with the policy-related sunk costs specified in their native form, not deflated by housing prices. The coefficient of the relative policy-related sunk costs is negative and significant across all horizons. The coefficient declines from the 24-month horizon to a minimum with the 48-month horizon, and then it 
Table 4. Sunk Cost and Car Usage: Structural Estimates

\begin{tabular}{|c|c|c|c|c|c|c|}
\hline Variable & $\begin{array}{c}\text { (a) } \\
\text { Rational } \\
\text { model }\end{array}$ & $\begin{array}{c}(b) \\
\text { Horizon: } \\
24 \text { months }\end{array}$ & $\begin{array}{c}(\mathrm{c}) \\
\text { Horizon: } \\
36 \text { months }\end{array}$ & $\begin{array}{c}(\mathrm{d}) \\
\text { Horizon: } \\
48 \text { months }\end{array}$ & $\begin{array}{c}(\mathrm{e}) \\
\text { Horizon: } \\
60 \text { months }\end{array}$ & $\begin{array}{c}(\mathrm{f}) \\
\text { Horizon: } \\
72 \text { months }\end{array}$ \\
\hline Gasoline price, $\beta_{1} \times 10$ & $\begin{array}{l}0.008^{* * *} \\
(0.003)\end{array}$ & $\begin{array}{l}0.008^{* * *} \\
(0.003)\end{array}$ & $\begin{array}{l}0.007^{* *} \\
(0.003)\end{array}$ & $\begin{array}{l}0.006^{* *} \\
(0.003)\end{array}$ & $\begin{array}{l}0.009^{* * *} \\
(0.003)\end{array}$ & $\begin{array}{l}0.009^{* * *} \\
(0.003)\end{array}$ \\
\hline Congestion, $\beta_{2}$ & $\begin{array}{l}0.006^{* * *} \\
(0.001)\end{array}$ & $\begin{array}{l}0.008^{* * *} \\
(0.002)\end{array}$ & $\begin{array}{l}0.010^{* * *} \\
(0.002)\end{array}$ & $\begin{array}{l}0.004^{* * *} \\
(0.001)\end{array}$ & $\begin{array}{l}0.003^{* *} \\
(0.001)\end{array}$ & $\begin{array}{l}0.004^{* * *} \\
(0.001)\end{array}$ \\
\hline Age,$\phi_{1} \times 10$ & $\begin{array}{l}0.104^{* * *} \\
(0.004)\end{array}$ & $\begin{array}{l}0.074^{* * *} \\
(0.010)\end{array}$ & $\begin{array}{l}0.247^{* * *} \\
(0.015)\end{array}$ & $\begin{array}{l}0.352^{* * *} \\
(0.014)\end{array}$ & $\begin{array}{l}0.310^{* * *} \\
(0.013)\end{array}$ & $\begin{array}{l}0.298^{* * *} \\
(0.014)\end{array}$ \\
\hline Age squared, $\phi_{2} \times 100$ & $\begin{array}{c}-0.011^{* * *} \\
(0.000)\end{array}$ & $\begin{array}{c}-0.008^{* * *} \\
(0.001)\end{array}$ & $\begin{array}{c}-0.021^{* * *} \\
(0.001)\end{array}$ & $\begin{array}{c}-0.026^{* * *} \\
(0.001)\end{array}$ & $\begin{array}{c}-0.020^{* * *} \\
(0.001)\end{array}$ & $\begin{array}{c}-0.016^{* * *} \\
(0.001)\end{array}$ \\
\hline Policy-related sunk costs, $\lambda_{41}$ & & $\begin{array}{c}-0.354^{* * *} \\
(0.084)\end{array}$ & $\begin{array}{c}-0.291^{* * *} \\
(0.066)\end{array}$ & $\begin{array}{c}-0.177^{* * *} \\
(0.058)\end{array}$ & $\begin{array}{c}-0.159^{* * *} \\
(0.053)\end{array}$ & $\begin{array}{c}-0.146^{* * *} \\
(0.052)\end{array}$ \\
\hline Ex-policy price, $\lambda_{42}$ & & $\begin{array}{c}-0.010 \\
(0.013)\end{array}$ & $\begin{array}{c}-0.007 \\
(0.010)\end{array}$ & $\begin{array}{c}-0.011 \\
(0.010)\end{array}$ & $\begin{array}{c}0.012 \\
(0.011)\end{array}$ & $\begin{array}{l}0.013 \\
(0.009)\end{array}$ \\
\hline Remaining horizon, $\lambda_{2} \times 10$ & & $\begin{array}{l}0.010^{* * *} \\
(0.002)\end{array}$ & $\begin{array}{c}-0.005^{* * *} \\
(0.002)\end{array}$ & $\begin{array}{c}-0.015^{* * *} \\
(0.002)\end{array}$ & $\begin{array}{c}-0.015^{* * *} \\
(0.002)\end{array}$ & $\begin{array}{c}-0.016^{* * *} \\
(0.002)\end{array}$ \\
\hline Observations & 36,931 & 36,931 & 36,931 & 36,931 & 36,931 & 36,931 \\
\hline Cars & 8,264 & 8,264 & 8,264 & 8,264 & 8,264 & 8,264 \\
\hline$R$-squared & 0.010 & 0.011 & 0.013 & 0.017 & 0.014 & 0.013 \\
\hline ln likelihood & $-23,854$ & $-23,839$ & $-23,803$ & $-23,727$ & $-23,773$ & $-23,794$ \\
\hline F-test statistic (vs. rational model) & NA & 10.768 & 33.905 & 83.563 & 54.030 & 40.091 \\
\hline$p$-value & NA & $<0.001$ & $<0.001$ & $<0.001$ & $<0.001$ & $<0.001$ \\
\hline Elasticity & NA & $0.049^{* * *}$ & $0.059^{* * *}$ & $0.048^{* * *}$ & $0.054^{* * *}$ & $0.065^{* * *}$ \\
\hline Elasticity s.e. & NA & $(0.012)$ & $(0.013)$ & $(0.016)$ & $(0.018)$ & $(0.023)$ \\
\hline
\end{tabular}

Notes. Estimated by ordinary least squares. The dependent variable is first difference of usage (in thousands of kilometers per month). Gasoline price is represented by CPI of 98 octane petrol, and Congestion is represented by the number of cars per kilometer. Age is in number of months since registration; Policy-related sunk costs and Ex-policy price are in millions of Singapore dollars. Robust standard errors clustered by car are in parentheses. The $F$-test evaluates the null hypothesis that coefficients of policy-related sunk costs, ex-policy price, and remaining horizon jointly are equal to zero; i.e., the rational model is valid.

${ }^{* * *} p<0.01 ;{ }^{* *} p<0.05 ;{ }^{*} p<0.1$.

rises for longer horizons. Across all horizons, the Fstatistics suggest rejection of the null hypothesis that $\lambda_{2}=\lambda_{41}=\lambda_{42}=0$. Apparently, the mental accounting parameters are significant.

Among the estimates, the 48-month horizon provides the best fit. The coefficient of relative policyrelated sunk costs, -0.095 (s.e. 0.044), implies an elasticity of 0.029 (s.e. 0.014). Comparing the models with raw sunk costs (see Table 4) and relative sunk costs (see Table 5), the results are quite similar. We slightly prefer the model with raw sunk costs as it is simpler.

\subsection{Further Robustness Tests}

The online appendix presents additional estimates that explore heterogeneous effects, by size of car and structure of government policy, and confirm robustness to alternative specifications of sunk costs and salience of COE premia. The online appendix also presents validation and falsification exercises, showing that higher sunk costs are associated with lower consumer expenditure on public transport (which is consistent with more driving) but are not significantly related to consumer expenditure at supermarkets or restaurants.
Furthermore, the online appendix investigates and rejects three alternative explanations based on selection: people who pay more for cars being subject to relatively more intense hedonic adaptation (Frederick and Lowenstein 1999), ${ }^{18}$ demand shocks leading people to buy cars at high prices followed by reversion to the mean driving intensity, and high initial driving leading to more frequent breakdowns and attenuation of driving.

\section{Hong Kong}

To provide a comparative analysis, we procured information on the same brand of cars for 962 cars sold between 2001 and 2013 in Hong Kong. We first qualify that the analysis of Hong Kong behavior might be less reliable than that of Singapore, which is based on a larger sample, more precise data on prices, and most important, a government policy that clearly specifies the sunk costs. However, to the extent that other governments do not explicitly impose sunk costs, the Hong Kong findings may be more broadly applicable.

Singapore and Hong Kong are quite similar-both are highly urbanized with a substantial middle class, 
Table 5. Relative Sunk Cost and Car Usage: Structural Estimates

\begin{tabular}{|c|c|c|c|c|c|c|}
\hline Variable & $\begin{array}{c}\text { (a) } \\
\text { Rational } \\
\text { model }\end{array}$ & $\begin{array}{c}\text { (b) } \\
\text { Horizon: } \\
24 \text { months }\end{array}$ & $\begin{array}{c}(\mathrm{c}) \\
\text { Horizon: } \\
36 \text { months }\end{array}$ & $\begin{array}{c}(\mathrm{d}) \\
\text { Horizon: } \\
48 \text { months }\end{array}$ & $\begin{array}{c}(\mathrm{e}) \\
\text { Horizon: } \\
60 \text { months }\end{array}$ & $\begin{array}{c}(\mathrm{f}) \\
\text { Horizon: } \\
72 \text { months }\end{array}$ \\
\hline Gasoline price, $\beta_{1} \times 10$ & $\begin{array}{l}0.007^{* *} \\
(0.003)\end{array}$ & $\begin{array}{l}0.007^{* *} \\
(0.003)\end{array}$ & $\begin{array}{l}0.006^{* *} \\
(0.003)\end{array}$ & $\begin{array}{r}0.006^{*} \\
(0.003)\end{array}$ & $\begin{array}{l}0.008^{* * *} \\
(0.003)\end{array}$ & $\begin{array}{l}0.008^{* * * *} \\
(0.003)\end{array}$ \\
\hline Congestion, $\beta_{2}$ & $\begin{array}{l}0.006^{* * *} \\
(0.001)\end{array}$ & $\begin{array}{l}0.006^{* * *} \\
(0.002)\end{array}$ & $\begin{array}{l}0.008^{* * *} \\
(0.002)\end{array}$ & $\begin{array}{c}0.002 \\
(0.001)\end{array}$ & $\begin{array}{c}0.002 \\
(0.001)\end{array}$ & $\begin{array}{l}0.003^{* *} \\
(0.001)\end{array}$ \\
\hline Age, $\phi_{1} \times 10$ & $\begin{array}{l}0.105^{* * *} \\
(0.004)\end{array}$ & $\begin{array}{l}0.073^{* * * *} \\
(0.010)\end{array}$ & $\begin{array}{l}0.246^{* * *} \\
(0.015)\end{array}$ & $\begin{array}{l}0.350^{* * *} \\
(0.015)\end{array}$ & $\begin{array}{l}0.305^{* * *} \\
(0.013)\end{array}$ & $\begin{array}{l}0.295^{\text {*** }} \\
(0.014)\end{array}$ \\
\hline Age squared, $\phi_{2} \times 100$ & $\begin{array}{l}-0.011^{* * *} \\
(0.000)\end{array}$ & $\begin{array}{l}-0.008^{* * *} \\
(0.001)\end{array}$ & $\begin{array}{l}-0.022^{* * *} \\
(0.001)\end{array}$ & $\begin{array}{l}-0.026^{* * *} \\
(0.001)\end{array}$ & $\begin{array}{l}-0.020^{* * *} \\
(0.001)\end{array}$ & $\begin{array}{l}-0.016^{* * *} \\
(0.001)\end{array}$ \\
\hline Relative policy-related sunk costs, $\lambda_{41}$ & & $\begin{array}{l}-0.268^{* * *} \\
(0.070)\end{array}$ & $\begin{array}{l}-0.166^{* * *} \\
(0.050)\end{array}$ & $\begin{array}{c}-0.095^{* *} \\
(0.044)\end{array}$ & $\begin{array}{l}-0.121^{* * *} \\
(0.040)\end{array}$ & $\begin{array}{l}-0.121^{* * *} \\
(0.039)\end{array}$ \\
\hline Relative ex-policy price, $\lambda_{42}$ & & $\begin{array}{c}0.003 \\
(0.012)\end{array}$ & $\begin{array}{l}0.000 \\
(0.009)\end{array}$ & $\begin{array}{c}-0.007 \\
(0.008)\end{array}$ & $\begin{array}{c}0.009 \\
(0.008)\end{array}$ & $\begin{array}{r}0.011^{*} \\
(0.006)\end{array}$ \\
\hline Remaining horizon, $\lambda_{2} \times 10$ & & $\begin{array}{l}0.008^{* * *} \\
(0.001)\end{array}$ & $\begin{array}{l}-0.007^{* * *} \\
(0.001)\end{array}$ & $\begin{array}{l}-0.017^{* * *} \\
(0.001)\end{array}$ & $\begin{array}{l}-0.015^{* * *} \\
(0.001)\end{array}$ & $\begin{array}{l}-0.016^{* * *} \\
(0.001)\end{array}$ \\
\hline Observations & 36,293 & 36,293 & 36,293 & 36,293 & 36,293 & 36,293 \\
\hline Cars & 8,121 & 8,121 & 8,121 & 8,121 & 8,121 & 8,121 \\
\hline$R$-squared & 0.010 & 0.011 & 0.013 & 0.017 & 0.014 & 0.013 \\
\hline In likelihood & $-23,428$ & $-23,413$ & $-23,377$ & $-23,302$ & $-23,348$ & $-23,369$ \\
\hline F-test statistic (vs. rational model) & NA & 10.966 & 34.530 & 85.109 & 53.448 & 39.254 \\
\hline$p$-value & NA & $<0.001$ & $<0.001$ & $<0.001$ & $<0.001$ & $<0.001$ \\
\hline Elasticity & NA & $0.043^{* * *}$ & $0.039^{* * *}$ & $0.029^{* *}$ & $0.047^{* * *}$ & $0.061^{* * *}$ \\
\hline Elasticity s.e. & NA & $(0.011)$ & $(0.012)$ & $(0.014)$ & $(0.015)$ & $(0.020)$ \\
\hline
\end{tabular}

Notes. Estimated by ordinary least squares. The dependent variable is first difference of usage (in thousands of kilometers per month). Gasoline price is represented by CPI of 98 octane petrol, and Congestion is represented by the number of cars per kilometer. Age is in number of months since registration; Relative policy-related sunk costs and Relative ex-policy price are the policy-related sunk costs and ex-policy price divided by the CPI-adjusted average price per square meter in units of thousands of Singapore dollars. Robust standard errors clustered by car are in parentheses. The $F$-test evaluates the null hypothesis that coefficients of relative policy-related sunk cost, relative ex-policy price, and remaining horizon jointly are equal to zero; i.e., the rational model is valid.

${ }^{* * *} p<0.01 ;{ }^{* *} p<0.05 ; * p<0.1$.

and their roads are subject to congestion. Hong Kong imposes a one-off registration tax, which presently ranges from $40 \%$ to $115 \%$, but does not limit the sales of new cars (no COE system or equivalent). Hence, buying a new car in Hong Kong does not involve any policy-induced sunk cost. The only possible sunk cost is, as in most other countries, related to the retail price.

Unlike Singapore, the government of Hong Kong does not publish the wholesale cost or retail price of cars. We assume that the wholesale cost is the same in Hong Kong and Singapore, which is reasonable, as both cities are major ports quite distant from the source of the cars. We procure the retail prices for several years, use the wholesale cost to impute the retail margin in Hong Kong, and then apply the same retail margin to calculate the retail prices in other years.

Table 6 reports summary statistics of the Hong Kong data. The sample is much smaller, partly due to the population of cars in Hong Kong being about onethird smaller than in Singapore (in 2007, the number of private cars was 372,203 in Hong Kong compared with 571,041 in Singapore) and partly due to incomplete data. Average monthly usage is 1,106 kilometers, which is about one-quarter lower than in the Singapore sample, while the average car is 50.8 months old, which is about the same as in the Singapore sample.

Table 6. Hong Kong: Summary Statistics

\begin{tabular}{llcccc}
\hline Variables & & Mean & s.d. & Min & Max \\
\hline Usage & 000's km/month & 1.106 & 0.535 & 0.244 & 4.347 \\
Age of car at last service & Months & 50.8 & 22.4 & 8 & 119 \\
Retail price & HK\$000,000's & 0.514 & 0.121 & 0.241 & 0.794 \\
Gasoline price & January 2006 $=100$ & 97.9 & 15.22 & 73.6 & 123.9 \\
Congestion & Cars per kilometer & 101.4 & 5.33 & 95.4 & 116.2 \\
\hline
\end{tabular}

Note. As of January 1, 2007, US\$1 = HK\$7.8. 
Figure 6. (Color online) Average Monthly Usage by Car Age (Hong Kong)

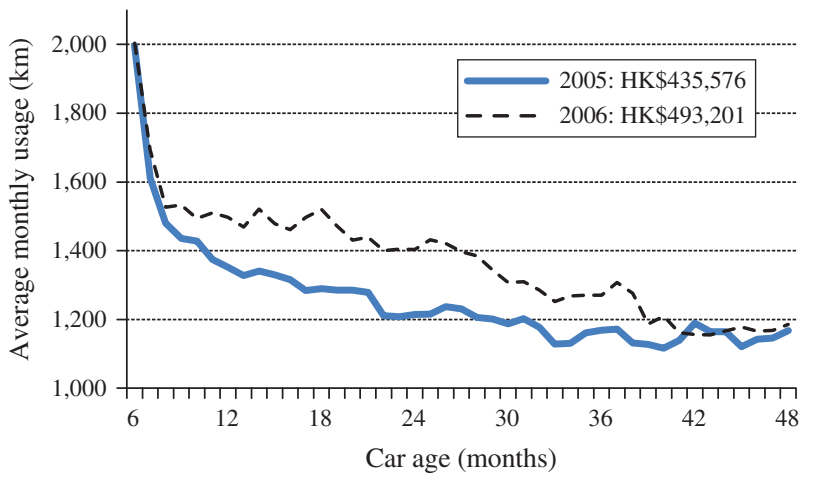

Note. For the most popular model in the sample (591 cars).

The big difference between the two markets is in the retail price of cars. The retail price in the Hong Kong sample ranges between HK\$241,000 and HK $\$ 794,000$, with an average of $\mathrm{HK} \$ 514,000$ (equivalent to US\$65,900), which is about $40 \%$ less than the Singapore average price. The index of gasoline prices rose from 73.6 in June 2001 to 123.9 in April 2013, while, over the same period, the level of congestion rose from about 95.4 to almost 116.2 cars per kilometer of road. Referring to Figure 6, we note attenuation in usage with age of the car and faster attenuation among cars for which prices were higher.

Table 7 presents the estimates of the behavioral model of mental accounting for Hong Kong car buyers. As a baseline, Table 7, column (a) reports the estimate of the rational model. The coefficient of age, $\phi_{1}$, is negative and significant, while the coefficient of the square of age, $\phi_{2}$, is not significant. This suggests that, among Hong Kong car buyers, the novelty effect kicks in without delay. In addition, the estimates suggest that gasoline prices do not affect usage significantly, although congestion does.

In contrast with Singapore, the government of Hong Kong does not impose sunk costs within specific horizons. So we estimate the behavioral model for alternative horizons, and we find that the effect of sunk costs is insignificant for horizons exceeding 36 months. However, there is significant evidence that the sunk cost fallacy affects driving over horizons of 20 to 36 months. For all horizons, the coefficient of the retail price, $\rho \lambda_{4}$ is negative and significant, and the $F$-test of the restrictions, $\lambda_{2}=\lambda_{4}=0$, can be rejected. Hence, the estimates suggest that drivers were influenced by sunk costs.

We focus on the 20-month horizon (see Table 7, column (b)), which has a marginally better fit. The coefficient of the retail price, $\rho \lambda_{4}=-0.023$ (s.e. 0.006),

Table 7. Hong Kong: Sunk Cost and Car Usage

\begin{tabular}{|c|c|c|c|c|c|c|}
\hline Variables & $\begin{array}{c}(\mathrm{a}) \\
\text { Rational } \\
\text { model }\end{array}$ & $\begin{array}{c}(b) \\
\text { Horizon: } \\
20 \text { months }\end{array}$ & $\begin{array}{c}(\mathrm{c}) \\
\text { Horizon: } \\
24 \text { months }\end{array}$ & $\begin{array}{c}(\mathrm{d}) \\
\text { Horizon: } \\
28 \text { months }\end{array}$ & $\begin{array}{c}(\mathrm{e}) \\
\text { Horizon: } \\
32 \text { months }\end{array}$ & $\begin{array}{c}(\mathrm{f}) \\
\text { Horizon: } \\
36 \text { months }\end{array}$ \\
\hline Gasoline price, $\beta_{1} \times 10$ & $\begin{array}{c}-0.004 \\
(0.011)\end{array}$ & $\begin{array}{c}-0.001 \\
(0.011)\end{array}$ & $\begin{array}{c}-0.000 \\
(0.011)\end{array}$ & $\begin{array}{c}-0.001 \\
(0.011)\end{array}$ & $\begin{array}{c}-0.001 \\
(0.011)\end{array}$ & $\begin{array}{c}-0.002 \\
(0.011)\end{array}$ \\
\hline Congestion, $\beta_{2}$ & $\begin{array}{c}0.014^{* *} \\
(0.005)\end{array}$ & $\begin{array}{c}0.009 \\
(0.006)\end{array}$ & $\begin{array}{c}0.008 \\
(0.006)\end{array}$ & $\begin{array}{c}0.007 \\
(0.006)\end{array}$ & $\begin{array}{c}0.007 \\
(0.006)\end{array}$ & $\begin{array}{c}0.009 \\
(0.006)\end{array}$ \\
\hline Age, $\phi_{1} \times 10$ & $\begin{array}{c}-0.037^{* * * *} \\
(0.014)\end{array}$ & $\begin{array}{c}-0.143^{* * *} \\
(0.031)\end{array}$ & $\begin{array}{c}-0.141^{* * *} \\
(0.037)\end{array}$ & $\begin{array}{c}-0.127^{* * *} \\
(0.044)\end{array}$ & $\begin{array}{c}-0.048 \\
(0.049)\end{array}$ & $\begin{array}{c}0.066 \\
(0.052)\end{array}$ \\
\hline Age squared, $\phi_{2} \times 100$ & $\begin{array}{c}-0.001 \\
(0.002)\end{array}$ & $\begin{array}{l}0.008^{* * *} \\
(0.003)\end{array}$ & $\begin{array}{l}0.007^{* *} \\
(0.003)\end{array}$ & $\begin{array}{c}0.005 \\
(0.004)\end{array}$ & $\begin{array}{c}-0.002 \\
(0.004)\end{array}$ & $\begin{array}{c}-0.010^{* *} \\
(0.004)\end{array}$ \\
\hline Retail price, $\rho \lambda_{4}$ & & $\begin{array}{c}-0.023^{* * *} \\
(0.006)\end{array}$ & $\begin{array}{c}-0.022^{* * *} \\
(0.005)\end{array}$ & $\begin{array}{c}-0.021^{* * *} \\
(0.006)\end{array}$ & $\begin{array}{c}-0.016^{* * *} \\
(0.006)\end{array}$ & $\begin{array}{c}-0.012^{* *} \\
(0.005)\end{array}$ \\
\hline Remaining horizon, $\lambda_{2} \times 10$ & & $\begin{array}{l}0.239^{* * *} \\
(0.052)\end{array}$ & $\begin{array}{l}0.212^{* * *} \\
(0.051)\end{array}$ & $\begin{array}{l}0.186^{* * *} \\
(0.055)\end{array}$ & $\begin{array}{c}0.090 \\
(0.055)\end{array}$ & $\begin{array}{c}-0.022 \\
(0.050)\end{array}$ \\
\hline Observations & 3,765 & 3,765 & 3,765 & 3,765 & 3,765 & 3,765 \\
\hline Cars & 962 & 962 & 962 & 962 & 962 & 962 \\
\hline$R$-squared & 0.023 & 0.027 & 0.026 & 0.026 & 0.025 & 0.025 \\
\hline ln likelihood & $-2,572$ & $-2,564$ & $-2,565$ & $-2,566$ & $-2,569$ & $-2,568$ \\
\hline$F$-test statistic & & 54.086 & 45.622 & 39.659 & 25.027 & 29.179 \\
\hline$p$-value & & $<0.001$ & $<0.001$ & $<0.001$ & $<0.001$ & $<0.001$ \\
\hline Elasticity & & $0.099^{* * *}$ & $0.113^{* * *}$ & $0.125^{* * *}$ & $0.110^{* * *}$ & $0.093^{* * *}$ \\
\hline Elasticity s.e. & & $(0.026)$ & $(0.026)$ & $(0.036)$ & $(0.041)$ & $(0.039)$ \\
\hline
\end{tabular}

Notes. Estimated by ordinary least squares. The dependent variable is first difference of usage (in thousands of kilometers per month). Gasoline price is represented by CPI of fuel, and Congestion is represented by the number of cars per kilometer. Age is in number of months since registration, and Retail price is in millions of Hong Kong dollars. Robust standard errors clustered by car are in parentheses The $F$-test evaluates the null hypothesis that coefficients of price and remaining horizon jointly are equal to zero; i.e., the rational model is valid.

${ }^{* * *} p<0.01 ;{ }^{* *} p<0.05 ;{ }^{*} p<0.1$. 
is negative and precisely estimated. This implies that the elasticity of usage with respect to the retail price is 0.099 (s.e. 0.026). The equivalent estimate for the Singapore drivers (see Table A3, column (c), in the online appendix) generates an estimated elasticity of 0.100 (s.e. 0.033), which is not significantly different. Overall, we infer that the estimates with Hong Kong data suggest that sunk costs related to the retail price do influence car buyers to increase driving. The mental accounting horizon is shorter than that among Singapore drivers, and the elasticity of driving with respect to the retail price is similar.

\section{Implications for Public Policy and Management}

Our findings of the sunk cost effect have implications for public policy and management strategy. The Singapore government manages traffic congestion through pricing of road usage and limiting car ownership. By design, the ARF and the COE embody substantial sunk costs. Our results suggest that these sunk costs resulted in the unintended consequence of stimulating driving (among those who did buy a car).

Between January 2009 and January 2013, the Singapore government reduced the relevant quota of COEs by 10,484 from 17,030 to 6,546 . The quota reduction coupled with growth of the Singapore economy resulted in the policy-related sunk cost rising by $\mathrm{S} \$ 13,038$, from $\mathrm{S} \$ 11,278$ to $\mathbf{S} \$ 24,316$. Using our preferred estimate, this increase in the sunk cost would be associated with an increase in monthly usage by $5.6 \%$, or 86 kilometers.

Hence, absent any other policy changes, the reduction in the COE quota would have affected road usage in two ways. On the basis of the average driving in our sample, the reduction in the number of cars would have reduced driving (as the government intended) by 16.2 million kilometers a month. ${ }^{19}$ On the other hand, mental accounting for sunk costs would have produced a countervailing effect. On the basis of our preferred estimate, the concomitant increase in the COE premium would have been associated with an increase in driving (which the government did not intend) by 0.9 million kilometers a month.

Indeed, the Singapore government appreciates that sunk costs affect driving: "[B]ecause sunk costs matter, the high fixed cost [sic] of car ownership can be inimical to our objective of restraining car usage. Thus, instead of simply relying on high car ownership cost to manage congestion on the road, the Government has been reducing vehicle taxes and shifting more towards usage charges" (Lew and Leong 2009, p. 19). ${ }^{20}$ Besides, the Singapore government has introduced incentives to use public transport (Yang and Lim 2017).

Clearly, managers may be subject to psychological biases. To the extent that managers are influenced by sunk costs, our findings have implications for marketing, accounting, and other strategies with respect to durable goods such as enterprise software, manufacturing equipment, and printers.

Producers of enterprise software such as Oracle and SAP sell systems as well as complementary postsale services to their installed base of customers. Similarly, manufacturers such as Tetrapak and Hewlett-Packard sell machinery as well as consumables to buyers of their equipment. The "razor-blade" model suggests setting a low price for the platform to entice customers and then setting higher prices on the complementary consumable to earn profits. If some buyers are myopic, this proposition holds even if supply is competitive (Gabaix and Laibson 2006).

By contrast, our findings suggest that the vendor ought to price the platform relatively high, so that the buyer will feel a need to mentally account for the sunk cost of the purchase and hence step up purchases of services and consumables. This implication is in accordance with the previous literature on mental accounting (Thaler 1980, pp. 49-50). Accordingly, the profit-maximizing price of the platform balances a lower price that attracts more myopic buyers and a higher price that induces more consumption through mental accounting for the sunk cost. The sunk cost fallacy tends to moderate competition among sellers on the platform. If a seller cuts the price of the platform, it attracts buyers from competitors, but it also reduces purchases of the consumable induced by the sunk cost.

On the buyer side, our findings suggest that managers need to proactively debias their decisions on usage of services and equipment involving large sunk costs. They must be careful to avoid mental accounting and spending more on services and usage to justify past sunk costs. They could subject themselves to the discipline of a thought experiment: How much would they spend on services and usage if sunk costs had been zero? Alternatively, it might be appropriate to revise the accounting system and procedures to eliminate reporting of sunk costs that might possibly bias managerial decisions.

More generally, our findings resonate with previous research on organizational behavior showing that managers escalate commitment in the face of unfavorable conditions (Staw 1976, Staw and Hoang 1995, Staw et al. 1997). To the extent that managers escalate commitment to rationalize earlier decisions, they need to proactively de-bias business strategy or be more closely supervised, or both. Such escalating behavior is another reason to revise accounting systems and procedures to eliminate reporting of sunk costs.

\section{Concluding Remarks}

Here, we investigate the effect of sunk costs on usage of a durable good. First, we develop a behavioral model 
that incorporates mental accounting for sunk costs and which nests rational behavior as a special case. In the context of car usage, we characterize the optimal dynamic driving behavior and how sunk costs might affect driving over time.

Then, we take the model to a proprietary panel data set of 8,264 cars between 2000 and 2013 in Singapore. Through structural estimates, we find compelling evidence of the sunk cost fallacy. People who incurred larger sunk costs in buying cars drove more and their driving attenuated faster with the age of the car. This effect of sunk costs was significant in the first 48 months of car ownership. Our results are robust to various checks including alternative explanations in terms of selection, the specification of sunk costs, and salience of sunk costs.

Our empirical finding suggests that individuals do not fully self-correct the effect of sunk costs on decision making even in repeated situations. Our estimates suggest that usage of durable goods increases with the sunk element of the price and attenuates over some horizon, and that the rate of attenuation increases with the sunk cost.

In contrast with our results, in field experiments, Ashraf et al. (2010) and Cohen and Dupas (2010) found no effect of price paid on consumer behavior. The disparity in findings may be due to differences in context. We investigate continuing usage of an expensive highinvolvement durable rather than a one-off purchase. The limitation of our study is that it is observational, being based on actual behavior in response to changes in sunk costs as a result of continuing government policy. Since there is no random assignment of sunk costs to different individuals, we cannot completely rule out the apparent sunk cost effect being due to some unobserved factor.

In future research, it would be good to investigate the factors that influence the sunk cost effect and how individuals differ in their sensitivity to sunk costs. Are individuals more sensitive to sunk costs where the stakes are larger and in a repeated situation, as suggested by the difference between our results and those of Ashraf et al. (2010) and Cohen and Dupas (2010)? Besides duration of time, what other factors can amplify or mitigate the effect of sunk costs on decision making? Can people learn to overcome the effect of sunk costs? If so, what debiasing techniques will be most effective?

The answers to these questions would help policy makers, managers, and consumers to correct sunk-cost bias and make more effective decisions across multiple contexts, including public policy, management of businesses and organizations, and personal choice.

\section{Acknowledgments}

The authors contributed equally and are listed in alphabetical order. The authors thank John List, the reviewers, Colin Camerer, Stefano Dellavigna, David Laibson,
Ulrike Malmendier, Minjung Park, Matthew Rabin, Matthew Shum, Richard Thaler, and seminar participants at Caltech, the Chinese University of Hong Kong, the Conference on Evidence-Based Public Policy Using Administrative Data in Singapore, Nanyang Technological University, Singapore Management University, the Workshop on Behavioral Economics and Policy Design in Singapore, the Singapore Economic Policy Forum, the Summer Institute in Competitive Strategy, the University of California at Berkeley, and the University of Michigan for comments and suggestions. The authors also thank Jia-An Tan, Danny Liew, Lee Kee Chong, Dinh Hoang Phuong Thao, and Tziyuan Chua for research assistance and, above all, two anonymous car dealers and the Land Transport Authority of Singapore for the data.

\section{Endnotes}

${ }^{1}$ In laboratory experiments, Phillips et al. (1991) and Friedman et al. (2007) also did not find evidence of the sunk cost fallacy.

${ }^{2}$ In organizational contexts, managers have been observed to increase investment in the face of deteriorating conditions. Such "escalation of commitment" has been interpreted as being made to rationalize the decision maker's earlier choice (Staw 1976, Staw and Hoang 1995, Staw et al. 1997). However, the same increase in investment could also be interpreted as the rational outcome of the decision maker's moral hazard, building of reputation (Kanodia et al. 1989, Camerer and Weber 1999), investment in a real option (Friedman et al. 2007, McAfee et al. 2010), or a memory shortcut (Baliga and Ely 2011). For instance, Camerer and Weber (1999) reanalyzed the Staw and Hoang (1995) data on escalation of commitment in the deployment of NBA basketball players. After accounting for the team managers' incentives through two-stage estimation, the effect of escalation of commitment was significantly reduced.

${ }^{3}$ Figure 1 presents usage from month 5 onward. Our data are based on service visits. For the brand of cars in our sample, the first scheduled service is at cumulative usage of 12,000 kilometers. So, with the average and standard deviation of usage being 1,545 and 529 kilometers a month, respectively, the first service of the car would be in the fifth month for the relatively heavy users (usage two standard deviations above average). We observe that about $2 \%$ of the cars had their first service before the fifth month. According to the service schedule, these cars should have had much higher than average mileage. To the contrary, many of these cars had lower than average mileage. We infer that these cars were sent for service because of defects. Accordingly, to avoid confounds resulting from defects, we focus on usage after the fifth month of ownership.

${ }^{4}$ At the end of the 10 th year, the owner can get a rebate of $50 \%$ of the ARF by deregistering the car. Owners who renew the COE for the same car must forfeit the $50 \%$ ARF rebate.

${ }^{5}$ In the behavioral model, we also allow for part of the retail price, unrelated to government policy, to be sunk.

${ }^{6}$ To the extent that congestion affects the COE premium, it is current congestion that affects the current $\mathrm{COE}$ premium. However, our empirical analysis below regresses current usage on the COE premium at the time of purchase, which is considerably earlier.

${ }^{7}$ Busse et al. (2015) find that weather affects consumer choice in buying new cars and show that the effect is due to projection bias and salience.

${ }^{8}$ The quadratic functional form, (3), may be interpreted as a Taylor series approximation of a more general benefit function that exhibits diminishing marginal benefit.

${ }^{9}$ The online appendix presents and rejects two alternative explanations based on selection: (1) demand shocks leading people to buy cars at high prices followed by reversion to the mean driving intensity and (2) high initial driving leading to more frequent breakdowns 
and attenuation of driving. The online appendix also provides a simple formalization of the difference between selection and attenuation due to the sunk cost fallacy.

${ }^{10}$ Empirically, the retail price of cars fell from 2000 to 2009, and then rose again. As car prices fell, some households may have purchased a second car and so, with two cars, would use each car relatively less, thus giving rise to a correlation between lower car prices and less usage of each car.

${ }^{11}$ Figure A1 in the online appendix depicts the distribution of the sample by length of ownership.

${ }^{12}$ Table A1 in the online appendix reports an estimate based on a larger sample of cars with usage within three standard deviations of the average; the sample comprises 8,401 cars with 37,291 observations. The same table also reports an estimate based on a smaller sample that includes all observations on cars with average monthly usage up to 3,000 kilometers per month.

${ }^{13}$ Figure A2 in the online appendix depicts the distribution of the sample by decile of home price over the years. Evidently, there is considerable variation over time. Our empirical strategy abstracts from this variation by specifying the dependent variable as the difference in usage between services. The differencing eliminates any individual fixed effects in usage such as those due to differences in household wealth.

${ }^{14}$ In the empirical model, (19), the coefficients of gasoline price and congestion are specified as $-\beta_{1}$ and $-\beta_{2}$, respectively. Hence, if $\beta_{1}>0$ and $\beta_{2}>0$, then driving decreases with the price of gasoline and congestion.

${ }^{15}$ Consider an increase in the policy-related sunk costs, $0.25 \times A R F+$ $0.2 \times C O E$, by $S \$ 10,000$. This would increase usage over a planning horizon of 48 months, with a larger increase in usage in the earlier months and smaller increase in usage in the later months. By Table 4, column (d), $\lambda_{41}=-0.177$; thus, the total increase in usage would be $-\lambda_{41} \cdot \sum_{t=1}^{48}[48-t+1]=2,082$ kilometers over 48 months, which amounts to an average of 43.4 kilometers a month. (Note that, in the estimating equation, the costs and price are measured in millions of Singapore dollars and usage measured in thousands of kilometers.) Dividing by the average monthly usage over the first 48 months, 1,550 kilometers, the proportionate change is $43.4 / 1,550=2.8 \%$. Dividing by the average sunk cost, $\$ \$ 17,154$, the proportionate change in the sunk cost is $10,000 / 17,154=58.3 \%$. Hence, the elasticity is $2.8 / 58.3=0.048$

${ }^{16}$ Our estimates are based on the normalization $\theta_{2}=1 / 2$. The estimated coefficients would change with the normalization, but the counterfactual effects would remain the same as the estimated coefficients adjust accordingly.

${ }^{17}$ As a robustness check, Table A2 in the online appendix reports the estimates for the various horizons with the car prices, policy-related sunk costs, and ex-policy prices deflated by the CPI.

${ }^{18}$ We test the hypothesis of selection combined with hedonic adaptation in two ways. One includes a lag of driving as an explanatory variable. Hedonic adaptation implies that more driving in the previous period would reduce the marginal benefit of driving in the current period, and hence reduce driving. Empirically, the coefficient of lagged usage interacted with the car price is not significant. The other test uses buying an expensive car and living in an expensive area as proxies for age and experience in car purchase. Buyers with more experience should be less subject to hedonic adaptation. The empirical results are mixed: buyers of more expensive cars exhibit less attenuation of usage over time, but buyers who live in more expensive areas do not exhibit less attenuation of usage over time.

${ }^{19}$ As explained above, the government sets the COE quota so that the overall car population (net of deregistered cars) does not a exceed specified target. Hence, actually, the reduction in COE quota is balanced by a fall in deregistrations.
${ }^{20}$ Lew and Leong (2009) mistook "sunk costs" as being synonymous with "fixed costs."

\section{References}

Agarwal S, Qian W (2014) Consumption and debt response to unanticipated income shocks: Evidence from a natural experiment in Singapore. Amer. Econom. Rev. 104(12):4205-4230.

Arkes HR, Blumer C (1985) The psychology of sunk cost. Organ. Behav. Human Decision Processes 35(1):124-140.

Ashraf N, Berry J, Shapiro JS (2010) Can higher prices stimulate product use? Evidence from a field experiment in Zambia. Amer. Econom. Rev. 100(5):2382-2413.

Baliga S, Ely JC (2011) Mnemonomics: The sunk cost fallacy as a memory kludge. Amer. Econom. J.: Microeconomics 3(4):35-67.

Busse MR, Pope DG, Pope JC, Silva-Risso J (2015) The psychological effect of weather on car purchases. Quart. J. Econom. 130(1): 371-414.

Camerer CF, Weber RA (1999) The econometrics and behavioral economics of escalation of commitment: A re-examination of Staw and Hoang's NBA data. J. Econom. Behav. Organ. 39(1):59-82.

Cohen J, Dupas P (2010) Free distribution or cost-sharing? Evidence from a randomized malaria prevention experiment. Quart. J. Econom. 125(1):1-45.

Eyster E (2002) Rationalizing the past: A taste for consistency. Working paper, Nuffield College, Oxford, UK. https:// www.nuffield.ox.ac.uk/Users/Eyster/papers/rationalize.pdf.

Frederick S, Loewenstein G (1999) Hedonic adaptation. Kahneman D, Diener E, Schwarz N, eds. Well-Being: The Foundations of Hedonic Psychology, Chap. 16 (Russell Sage Foundation, New York).

Friedman D, Pommerenke K, Lukose R, Milam G, Huberman BA (2007) Searching for the sunk cost fallacy. Experiment. Econom. 10(1):79-104.

Gabaix X, Laibson D (2006) Shrouded attributes, consumer myopia, and information suppression in competitive markets. Quart. J. Econom. 121(2):505-540.

Genesove D, Mayer C (2001) Loss aversion and seller behavior: Evidence from the housing market. Quart. J. Econom. 116(4): 1233-1260.

Gourville JT, Soman D (1998) Payment depreciation: The behavioral effects of temporally separating payments from consumption. J. Consumer Res. 25(September):160-174.

Hastings J, Shapiro JM (2013) Fungibility and consumer choice: Evidence from commodity price shocks. Quart. J. Econom. 128(4):1449-1498.

Just DR, Wansink B (2011) The flat-rate pricing paradox: Conflicting effects of "all-you-can-eat" buffet pricing. Rev. Econom. Statist. 93(1):193-200.

Kanodia C, Bushman R, Dickhaut J (1989) Escalation errors and the sunk cost effect: An explanation based on reputation and information asymmetries. J. Accounting Res. 27(1):59-77.

Lew YD, Leong WY (2009) Managing congestion in Singapore-A behavioural economics perspective. Journeys (May):15-22.

List JA (2003) Does market experience eliminate market anomalies? Quart. J. Econom. 118(1):41-71.

List JA (2004) Neoclassical theory versus prospect theory: Evidence from the marketplace. Econometrica 72(2):615-625.

McAfee RP, Mialon HM, Mialon SH (2010) Do sunk costs matter? Econom. Inquiry 48(2):323-336.

Phillips OR, Battalio RC, Kogut CA (1991) Sunk and opportunity costs in valuation and bidding. Southern Econom. J. 58(1): 112-128. 
Staw BM (1976) Knee-deep in the big muddy: A study of escalating commitment to a chosen course of action. Organ. Behav. Human Performance 16(1):27-44.

Staw BM, Hoang H (1995) Sunk costs in the NBA: Why draft order affects playing time and survival in professional basketball. Admin. Sci. Quart. 40(3):474-494.

Staw BM, Barsade SG, Koput KW (1997) Escalation at the credit window: A longitudinal study of bank executives' recognition and write-off of problem loans. J. Appl. Psych. 82(1):130-142.
Thaler R (1980) Towards a positive theory of consumer choice. J. Econom. Behav. Organ. 1(1):39-60.

Thaler R (1990) Anomalies: Saving, fungibility, and mental accounts. J. Econom. Perspect. 4(1):193-205.

Thaler R (1999) Mental accounting matters. J. Behav. Decision Making 12(3):183-206.

Yang N, Lim YL (2017) Temporary incentives change daily routines: Evidence from a field experimentation on Singapore's subways. Management Sci. Forthcoming. 